Portland State University

PDXScholar

$5-12-1978$

\title{
Aspekte des Charakterbegriffs im Werk von Bertolt Brecht
}

Brigitte DeWolfe

Portland State University

Follow this and additional works at: https://pdxscholar.library.pdx.edu/open_access_etds

Part of the German Literature Commons Let us know how access to this document benefits you.

\section{Recommended Citation}

DeWolfe, Brigitte, "Aspekte des Charakterbegriffs im Werk von Bertolt Brecht" (1978). Dissertations and Theses. Paper 2868.

https://doi.org/10.15760/etd.2862

This Thesis is brought to you for free and open access. It has been accepted for inclusion in Dissertations and Theses by an authorized administrator of PDXScholar. Please contact us if we can make this document more accessible: pdxscholar@pdx.edu. 
AN ABSTRACT OF THE THESIS OF Brigitte DeWolfe for the Master of Arts in German presented May 12, 1978.

Title: ASPEKTE DES CHARAKTERBEGRIFFS IM WERK VON BERTOLT BRECHT

(BRECHT'S CONCEPT OF CHARACTER AND ITS INFLUENCE ON THE CONTENT AND STYLE OF HIS WORKS)

APPROVED BY MEMBERS OF THE THESIS COMMITTEE:

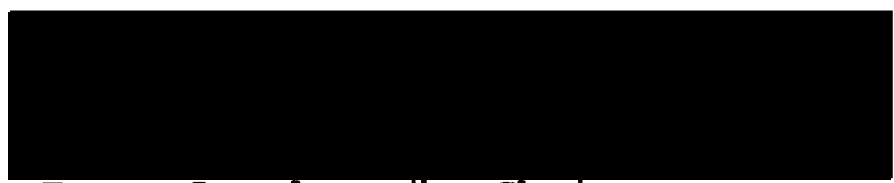

Franz Langhammeł, Chairman
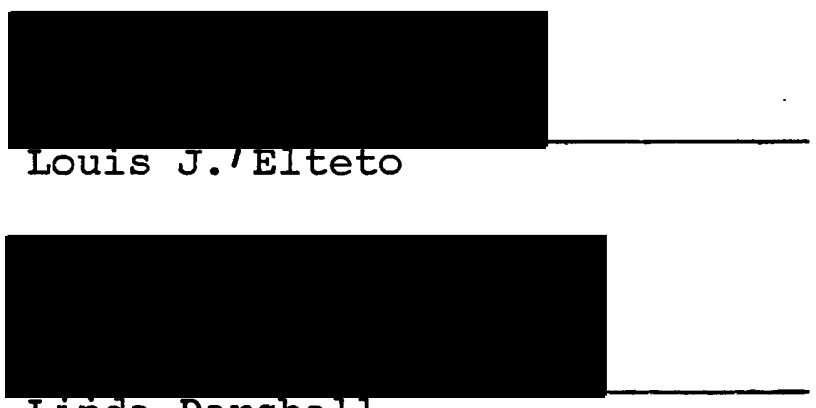

Brecht's concept of character, based on the Marxistsocialist premise of the perfectibility of man, is one of the most important aspects of his work. He believes that man's character is comparable to an atom, constantly falling apart and re-assembling itself. He states that man should be defined by his contradictory actions. 
With this view of man, several assumptions of the traditional theater no longer hold. There is no stalwart hero to pit the strength of his character against fate, there is no moral code by which he could act, since all is seen as being in flux and ethics are decided upon according to the demands of each specific situation.

Since the heart of tragedy usualiy is the struggle of a heroic figure against fate, and since Brecht's figures are changeable and no longer heroic, the premises of tragedy no longer exist. Furthermore, the hero's character can no longer serve to advance the action of the play. The environment has to serve now as a stimulus for its progress.

Although Brecht believes in the eventual advent of a "golden age," he presents his figures as being engaged in a daily struggle, winning, losing and compromising.

Such figures no longer can be shown by traditional acting methods; Brecht invented the "epic" way of acting to accommodate them. New methods of observation and expression are the result of these new "heroes." Thus, Brecht's concept of character serves to convey his idea of man's existential possibilities, but also causes stylistic changes in his work. 
ASPEKTE DES CHARAKTERBEGRIFFS IM WERK

VON BERTOLT BRECHT

by

Brigitte DeWolfe

A Thesis submitted in partial fulfillment of the requirements for the degree of

MASTER OF ARTS

in

GERMAN

Portland State University

1978 
TO THE OFFICE OF GRADUATE STUDIES AND RESEARCH:

The members of the Committee approve the thesis of Brigitte DeWolfe presented May 12, 1978.

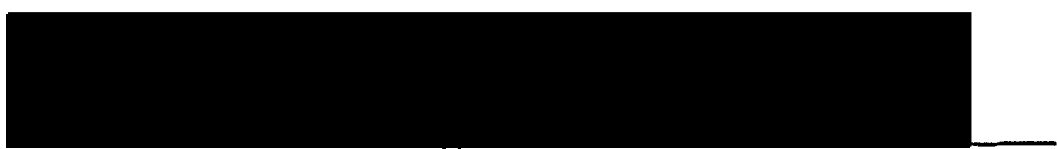

Franz Langhammer, Chairman

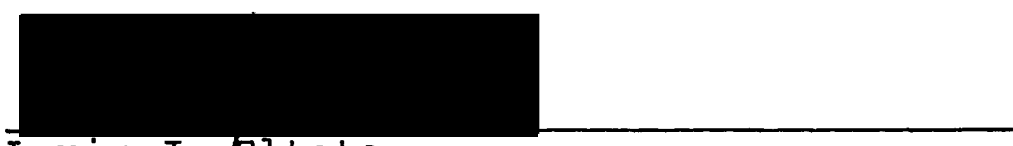

Louis J. Elteto

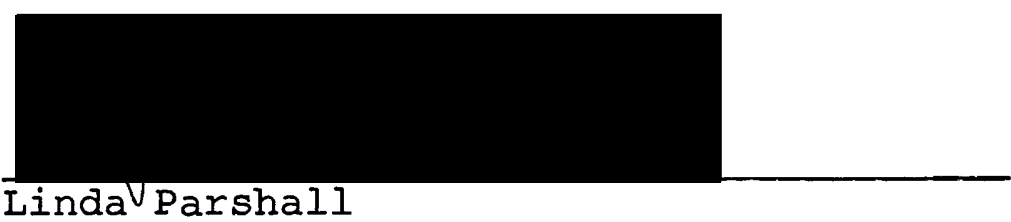

APPROVED
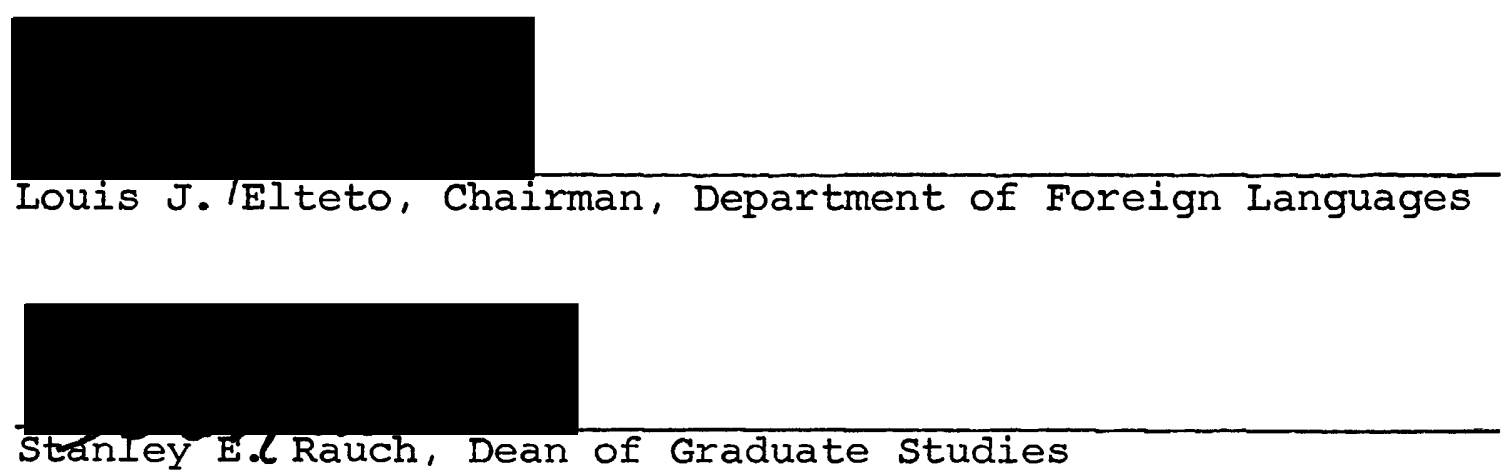

Stanley E.L Rauch, Dean of Graduate Studies 


\section{VORWORT}

Obwohl Brechts Opus traditionell in drei oder vier Phasen unterteilt wird und der Beweis gefthrt werden kann, dass sich sein Blickpunkt mehrmals geändert hat, ist das Phänomen einer mangelnden "Charakterfestigkeit" seiner Helden konstant. Es soll hier versucht werden, zu beweisen, dass diese Abkehr vom vorbildlichen, charakterlich konsequenten Helden zur "charakterlosen," sich moralisch dauernd verandernden und als Studierobjekt konzipierten Hauptfigur ein wichtiges Lehrmittel Brechts war und Inhalt sowohl als auch Form vieler seiner stthcke wesentlich beeinflusste. 
INHALTSVERZEICHNIS

SEITE

VORWORT

KAPITEL

I. DIE BEDEUTUNG DES CHARAKTERBEGRIFFS

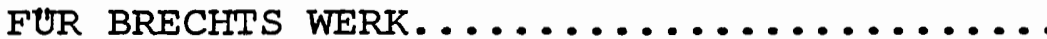

II. DER "CHARAKTER" UND WIE ER SICH MANI-

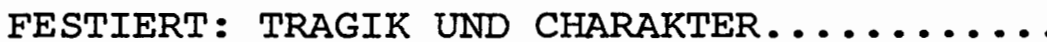

III. SCHILLERS THEATER ALS MORALISCHE ANSTALT UND BRECHTS CHARAKTERBEGRIFF:

EIN VERGLEICH................... II

IV. REALISMUS IN DER DARSTELLUNG: DER GENAU BEOBACHTENDE BLICK UND PHILOSOPHISCHWISSENSCHAFTLICHE SYSTEME ALS GRUNDLAGE

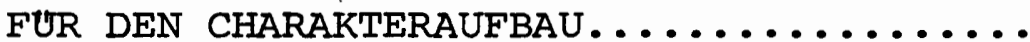

V. DIE UMWELT ALS ERSATZ FUR DEN CHARAKTER, ALS ANSPORN FUR DIE HANDLUNG............ 28

VI. DER EPISCHE CHARAKTER ALS LEHR- UND STIT.MITTEL................... 33

VII. CHARAKTER DES GEGENSPIELERS........... 43

VIII. DER "GESPALTENE MENSCH"............ 46

IX. DIE DARSTELLUNG DES EPISCHEN CHARAKTERS AUF DER BUHNE................. 50

X. DIE NEUE ETHIK: DIE "PRODUKTIVE HALTUNG" ALS ERSATZ FUR DAS TRADITIONELLE MORALSYSTEM. 


\section{DIE BEDEUTUNG DES CHARAKTERBEGRIFFS FUR BRECHTS WERK}

Auf Brechts Grabstein stehen seinem Wunsch gemäss nur sein Name und sein Geburts-und Todesjahr. Als zweitbeste Alternative wahlte er den Satz: Er hat Vorschläge gemacht, wir haben sie angenommen... Am Ende seines Lebens zurtlckschauend sah er seine Berufung als die eines Lehrers. Er verfolgte dabei zwei Hauptzwecke: erstens wollte er den Menschen ein neues Schauen beibringen, den verfremdeten Blick, der Gewohntes erstaunlich macht. Zweitens wollte er, dass seine Zuschauer die Konsequenzen aus dem neuen Sehen zogen und ihr Verhalten anderten. Das Resultat sollte eine bessere Welt sein, die zwar nicht sogleich zu erreichen war, die aber fur die "Nachgeborenen" heraufdummern könnte.

Lehrer und Kthstler verschmolzen bei Brecht zu einer neuen, fruchtbaren Einheit. Frisch schreibt in seinen

\section{Erinnerungen an Brecht:}

Was man vor allem mit zunehmender Entfernung, fur den ganzen Brecht zu halten versucht ist: der lehrende Brecht, der Verkthnder ästhetischer Begriffe, der Anti-Aristoteles... Die Meinung von Brecht, dass die heutige welt auf dem Theater wiedergegeben werden konne, aber nur, wenn sie als veründerbar aufgefasst wird, erscheint wie die obersetzung einer schlichten Kunst-Erfahrung in ein politisches Programm thber den Kunst-Akt hinaus: der Wille, die Welt 
zu verändern, als eine Verlängerung des künstlerischen Gestaltungsdranges. I

Bei seiner neuen Definition des Menschen halfen Brecht die Prinzipien des Marxismus. War also Brecht zuerst Künstler oder Marxist oder sozialer Reformator? Kohlhase kommentiert hiezu:

Es ist demnach nicht so, dass am Beginn der marxistischen Entwicklung Brechts eine soziale Anklage stand, wie sie etwa Engels in seiner Beschreibung der "Lage der arbeitenden Klasse in England" vorbrachte. Whirend die historische Wurzel des Sozialismus der Anblick des Elends war, wurde Brecht durch ein literarisches Problem zur Beschaftigung mit der neuen Gesellschaftslehre angeregt. (Es war ihm deutlich geworden, dass seine bisherigen dramatischen versuche in ein unlusbares Dilemma geraten waren: Entweder liessen sich die Themen, die ihn vor allem interessierten, nicht darstellen oder aber sie bussten ihre wahrheit ein, wenn er sie dramatisch umfunktionierte. Er musste eine neue Darstellungsweise suchen, fthr die er die theoretische Erklurung im Marxismus fand.)

'Es war wohl kaum Mitleid oder Suchen nach Gerechtigkeit, die Brecht zu Marx und Lenin fthrten,' schreibt Mayer: 'es war auch nicht das revolutionäre Pathos, das ihn am Sozialismus anzog.' Er ging der marxistischen Gesellschaftslehre auf die Spur, um einen Ausweg aus seinen ungelosten literarischen Problemen zu finden - und wurde von ihr unwiderstehlich fasziniert. Dieser Weg vom expressionistischen Dramatiker, vom Vertreter einer tendenzlosen Sachlichkeit und eines amoralischen Artismus, zum "gelernten" Marxisten wurde durch den Philosophen Korsch vorbereitet...2

Es liegt ausserhalb des Bereichs dieser Arbeit, genau zu analysieren, welchen Anteil an seinem Kunstlertum die verschiedenen Quellen hatten, aus denen Brecht schopfte. Fest steht, dass er die Welt, und darin den Menschen, als veränderbar darstellen wollte. Nur so vermeinte er die Umerziehung des Volkes bewerkstelligen $z u$ können, mit dem 
Ziel, die Abäderung einer Gesellschaftsform zu erreichen, die in den modernen westlichen Industrieländern vorherrschend war und die es den meisten Menschen unmoglich machte, sich einen "Platz an der Sonne" zu ergattern.

Diese Veränderlichkeit des Charakterbegriffs wirkte sich auch technisch entscheidend aus: Da kontinuierliche Charaktereigenschaften nicht mehr existieren, können sie auch nicht mehr als "Motor" der Handlung im Drama verwendet werden. Episodenhafter Aufbau in Form von "Bilderbogen" ersetzt den unausweichlich logischen Verlauf charakterbedingter Dramen. Die Triebfedern fur das Verhalten der Figuren sind nunmehr gesellschaftliche Zustande und wirtschaftliche Interessen.

Die neue realistische Sehweise beeinflusste damit sowohl die Form als auch den Inhalt von Brechts Werk. Die Darstellung des Menschen auf der Bthne und die Beeinflussung des Menschen im Zuschauerraum verschmolzen im Kunstwerk, dem Erziehungsmittel.

Erziehung war ftur Brecht neben der Vermittlung des faktischen Wissens und der Ubung in Fertigkeiten (fur die er thrigens viel Respekt bewies) vor allem die Erziehung zu einer neuen Haltung. Charaktererziehung, wie sie damals praktiziert wurde, bedeutete, dass Normen aufgestellt und bestimmte erwhinschte Qualitatten gefordert und gepriesen wurden. Verlief alles wie geplant, dann war das Resultat ein "guter Burger," ein Mensch mit Respekt von der Autorität, der die gegenwärtigen Zustände bejahte und 
unterstutzte, ohne Rthcksicht darauf, ob sie in seinem Interesse waren oder nicht. Es war das Gegenteil dessen, was Brecht zu erreichen hoffte.

Da Charaktererziehung, Moral und Verhalten eng zusammenhängen, soll hier untersucht werden, wie Brecht als Sttuckeschreiber und Erzieher sich zu dem Begriff des Charakters als moralische Einheit einerseits und als Trăger dramatischer Impulse andererseits gestellt hat. In beiden Beziehungen hat er mit der Tradition gebrochen und es ist behauptet worden, dass man von Charakter im Sinne einer Konsistenz des Betragens bei seinen Figuren nicht mehr sprechen kann. Er hat daftr oft die Idee der Haltung eingesetzt, ein Begriff der zwar auf weite Sicht von einem ethischen Ziel, aber von Tag zu Tag eher von situationsbedingten Erwägungen bestimmt ist. 
KAPITEL II

DER CHARAKTER UND WIE ER SICH MANIFESTIERT;

TRAGIK UND CHARAKTER

Sucht man nach Definitionen des Wortes "Charakter," so findet man eine ganze Reihe von Deutungen, die sich nur teilweise decken. In modernen Psychologietexten ist das Wort "Charakter" tberdies oft mit Personlichkeit gleichgesetzt, ein Begriff der viel umfassender sein kann und nicht unbedingt sittliche Werte enthalt. Die Brockhaus Enzyklopadie sagt ther Charaktererziehung:

Persठnlichkeitserziehung, eines der Hauptziele aller an der Erziehung beteiligten Mächte... die Erziehung zu sicherem Urteil, selbständigem Handeln, Entschlusskraft und Verantwortungsbereitschaft... Zur Charaktererziehung gehoren: die Ausbildung fester Gewohnheiten, der Aufbau gesitteter ordnungen, die von Kindern als selbstverständich erfahren werden, die Orientierung an ethischen Normen, die anerkannt und gelebt werden konnen.1

Vorher heisst es: "Charakter demnach ist verantwortungsbewusstes, verlassliches und folgerichtiges verhalten!"

Das Grosse Duden Lexikon betont "die geistig-seelische Prăgung eines Menschen, die die Einheitlichkeit und Stetigkeit seiner Willensrichtungen... bestimmt." ${ }^{2}$ Jakob und Wilhelm Grimm definieren "charakterlos" als "sibi non constans." 3

Hehlmann sieht im Charakter die 
Person; im engsten Sinne die Wesensart einer Personlichkeit im Hinblick auf ihre Bewathrung sittlichen Aufgaben gegentber... die kernhafte Sphäre der Persönlichkeit, aus der heraus der Mensch verantwortlich handelt und wertet. 4

Wilhelm Reich, ein Schuler Freuds, sieht den Charakter eines Menschen als seinen Panzer (armor), und daher als etwas Negatives.

The character consists in a chronic alteration of the ego which one might describe as a rigidity. It is the basis of the becoming chronic of a person's characteristic mode of reaction. Its meaning is the protection of the ego against external and internal dangers. As a protection mechanism which has become chronic it can rightly be called an armor. This armor inevitably means a reduction of the total psychic mobility. This reduction is alleviated by relationships with the outer world which are not conditioned by the character and thus are atypical. There are "gaps" in the armor through which libidinal and other interests are put out and pulled back like pseudopodia. The armor, however, is to be thought of as mobile. It operates according to the pleasure-unpleasureprinciple. In unpleasurable situations the armoring increases, in pleasurable situations it decreases. 5

Nandor Fodor tbersetzt Freuds Charakterdefinition so:

What we call character of the person is built up to a large extent from the material of sexual excitations: it is composed of impulses fixed since infancy and won through sublimation, and of such structures as are destined to suppress effectually those ${ }_{6}$ erverse feelings which are recognized as useless. $6^{\text {p }}$

In diesen beiden Definitionen erscheint Charakter als

Verhärtung gegen Impulse von Innen und Druck von Aussen.

Kimble und Garmezy sehen den Charakter vom soziolo-

gischen Standpunkt:

We could define personality as the unique organization of fairly permanent characteristics that set the individual apart from other individuals 
and, at the same time, determine how others respond to him... A personality trait is simply an action tendency or disposition that characterizes a person.7

Lindsey, Hall und Thompson schliessen ihrer Definition eine positive Wertung des Charakterbegriffes an:

Although there are many conceptions of personality, psychologists generally agree that personality refers to an organization of more of less permanent qualities that characterize an individual... Coherence or consistency in the way one is put together is essential because unless a consistent set of needs, goals and ideals underlies a person's decisions, they will move in random or confused directions. 8

Altere Theorien versuchen, den Charakter als Nebenerscheinung von körperlichen Eigenschaften zu erklüren. Hippokrates stellte die Theorie der vier Temperamente auf, die von vier körperflussigkeiten abhängen sollten. Kretschmer versuchte Ahnliches mit Knochenmessungen, Sheldon fand Parallelen zwischen bestimmten körpertypen und Charakterzthgen. Hier war Charakter also nicht erworben sondern ein Zufall der Geburt.

Neben vererbten Einflussen ist der Charakterinhalt auch von den sittlich-religiosen sowie wirtschaftlichen Werten einer Gesellschaft abhängig. Jede Gemeinschaft hat ihre eigenen Ideale.

Trotz aller dieser verschiedenen Anschauungspunkte fallen zwei Grundbedingungen des Charakterbegriffs ins Auge: das Sich-Gleichbleibende, Voraussagbare des Charakters und die Annahme, dass Charakter etwas Fertiges ist. Brecht hat das zurllckgewiesen. Charakter ist ftur ihn ein 
bthrgerlicher Begriff gestltzt auf ein festes Weltbild. Aber, um Brecht zu umschreiben, die Verhaltnisse, die sind nicht mehr so. Alles fliesst, daher gibt es keine festgelegte Moral, ja sie wäre ein Hindernis in der Entwicklung des Menschen. Charakter ist keine gegebene Grösse, sondern ein Prozess. Anders ausgedrulckt: "Das kontinuierliche Ich ist eine Mythe. Der Mensch ist ein immerwährend zerfallendes und neu sich bildendes Atom." 9 Die Persönlichkeit eines Menschen ist die Summe seiner widersprthchlichen Handlungen.

Dr. Wesley von der Portland State Universität deutet auch darauf hin, dass, vom Standpunkt der Volkserziehung aus gesehen, der Mensch, dem feste Grundätze mitgegeben wurden, ein gltucklicherer Mensch sein wird als einer, der in der Erwartung von Wechsel und Wandel erzogen wurde und daher seine Handlungsmotive immer neu zu rechtfertigen hat. Es ist aber gerade diese stetige Bereitschaft zur Neuinterpretierung der Umstande, die Brecht von seinen Figuren und Zuschauern erwartet. Ein fester Charakter garantiert ein gutes Gewissen. Ein "charakterfreier" Mensch im Sinne Brechts ist ständig dem Risiko des Fehlhandelns ausgesetzt, aber nur in dieser Lebensform liegt der wahre Verdienst und Fortschritt fur die Menschheit.

Walcutt, in seinem ersten Kapitel mit dem Titel "What is Charakter?"10 deutet darauf hin, dass der Charakterbegriff traditionell zwischen zwei Extremen liegt, nămich der Identifizierung mit einem unsichtbaren "inneren Wesen" 
oder mit ausserlich sichtbaren Taten. Es erhebt sich nun die Frage: Gibt es einen Charakter per se, unabhangig von sichtbaren Handlungen? Walcutt weist darauf hin, dass diese Kontroverse schon seit Aristoteles die Gemuter erregt. Wenn Emerson mit den Romantikern sagt, "Essence precedes existence," und "The event is the print of your form," so behauptet er damit, dass Taten nur ein zufalliges und sekundares Resultat des inneren Seins darstellen. Wenn die Existentialisten dagegen behaupten, dass der Wert eines Menschen erst im Augenblick des Todes festgestellt werden kann, und zwar einzig im Rtkckblick auf seine Taten, so sind wir am anderen Ende des Spektrums angelangt. Brecht halt es hier mit den Existentialisten. Er weist Monologe, die innere Zustande und seelische Zerrissenheit darlegen, als Zeitverschwendung zurtuck. Denken muss eingreifendes Denken sein, die Vorbereitung zur Tat. Der "harmlose," nur auf sich bezogene Mensch ist wertlos. Es zahlt nur der nttzliche Mensch.

Brecht akzeptiert Charakteranlagen und Eigenschaften nicht als primäres Handlungsmotiv. Er hat Nachdruck darauf gelegt, dass seine Figuren aus widersprtbchlichen "Handlungen," die auf widersprtuchliche Interessen zurthckzufthren seien, aufgebaut werden sollten. Entdeckte man bei Mutter Courage etwa eine Charaktereigenschaft, wäre sie als "conditioned reflex" $z u$ verstehen, als eine Art gesellschaftlich bedingte Verwachsung und Verkrtppelung. Als Vergleich fur diesen Zustand haben Brecht schwache Obstbalumchen aus 
Hinterhofen der inneren stadt gedient. Es ist nicht der Charakter eines solchen Bäumchens, unfruchtbar zu sein, sondern der Mangel an Licht und Nahrung ist schuld an seinem Defekt. Verbessert man die Umwelt, so verschwinden auch die dem Bäumchen anhaftenden Fehler.

Schliesslich ist noch zu erwathnen, dass das Tragische meist aus einem Konflikt zwischen der inneren struktur eines. Menschen (dem "Charakter"), und den Forderungen der Umwelt besteht. Da Brecht alles als im Fluss begriffen sieht, einschliesslich des Charakters des Menschen, wird eine klassische Tragödie unmöglich. Ausserdem, so meint Galilei in loco autoris, ist das individuelle Ungluck uninteressant, denn es stammt nur von mangelhafter Berechnung. Il Brechts Hauptfiguren sind als Typen gedacht, sie stehen fthr eine Klasse und nur unter diesem Blickpunkt ist ihr Schicksal aufschlussreich.

Obwohl einige Kritiker dennoch klassisch-tragische Elemente in Brechts Schauspielen sehen, besonders in der Massnahme, hat der Stuckeschreiber Brecht keinesfalls Tragodien mit kathartischem Effekt schreiben wollen, sondern Lehrstucke als Beitrag zum Bauen einer besseren welt. 
Friedrich Schillers opus gehorte zu den wichtigsten Einflussen auf Brechts Werk, und zwar sowohl im Sinne der imitativen Verarbeitung als auch im Sinne der Karikatur und des Protests. Mayer bemerkt hiezu:

Dass diese Beziehung zwischen Brecht und der Klassik nicht nur fur den stuckeschreiber selbst von jeher als Auseinandersetzung gegeben war, sondern in der Tat auch der Nachwelt hilft, die spezifische Bedeutung Brechts in unserer Literatur genauer zu sehen, also jenseits allen Geschwätzes um den Kommunisten Brecht, der 'trotzdem' ein Dichter gewesen sei, wird immer starker evident. Dieser Brecht-Auseinandersetzung bei Max Frisch, die einem Zurtuck des Verfassers von 'Biedermann' und 'Andorra' zu Schiller gleichzukommen scheint, entspricht gleichzeitig bei Friedrich Durrenmatt der Versuch, Schiller und Brecht als zwei Exponenten einer Literatur zu verstehen, die man zu tuberwinden habe. Was Durrenmatt an Brecht stort, ist das SchillerElement in Brecht. I

Brecht selbst betonte, dass er nicht im Namen der Moral, sondern im Namen der Geschadigten sprechen wolle, wie er das in seiner Kohlhaasbearbeitung tat. Trotzdem wollte er sein episches Theater auch als "moralische Anstalt" betrachtet wissen. Im folgenden zitat versucht er, Schillers Konzept des Lehrtheaters von seinem eigenen abzugrenzen.

Nach Friedrich Schiller soll das Theater eine moralische Anstalt sein. Als Schiller diese 
Forderung aufstellte, kam es ihm kaum in den Sinn, dass er dadurch, dass er von der Bthne herab moralisierte, das Publikum aus dem Theater treiben konnte. $\mathrm{Zu}$ seiner zeit hatte das Pubm likum nichts gegen das Moralisieren einzuwenden. Erst spatter beschimpfte ihn Friedrich Nietzsche als den Moraltrompeter von sackingen. Nietzsche schien die Beschaftigung mit Moral eine trubselige Angelegenheit, Schiller erblickte darin eine durchaus vergntigliche. Er kannte nichts, was amtisanter und befriedigender sein konnte, als Ideale zu propagieren...

Auch gegen das epische Theater wandten sich viele mit der Behauptung, es sei zu moralisch. Dabei traten beim epischen Theater moralische Erorterungen erst an zweiter stelle auf. Es wollte weniger moralisieren als studieren. Allerdings, es wurde studiert, und dann kam das dicke Ende nach: die Moral von der Geschichte. Wir konnen natthrlich nicht behaupten, wir hätten uns aus lauter lust zu studieren und ohne anderen handgreiflicheren Anlass ans studium gemacht und seien dann durch die Resultate unseres studiums vollig tberrascht worden. Es gab da zweifellos einige schmerzliche Unstimmigkeiten in unserer Umwelt, schwer ertragbare Zustande, und zwar Zustände, die nicht nur aus moralischen Bedenken heraus schwer zu ertragen waren...

Zweck unserer Untersuchungen war es, Mittel ausfindig zu machen, welche die betreffenden schwer ertragbaren Zustande beseitigen konnten. Wir sprachen namlich nicht im Namen der Moral, sondern im Namen der Geschadigten. Das sind wirklich zweierlei Dinge, denn oft wird gerade mit moralischen Hinweisen den Geschadigten gesagt, sie mussten sich mit ihrer Lage abfinden. Die Menschen sind fthr solche Moralisten fth die Moral da, nicht die Moral fur die Menschen.

Immerhin wird man aus dem Gesagten entnehmen konnen, wieweit und in welchem Sinn das epische Theater eine moralische Anstalt ist. 3

Obwohl Brecht also Schillers Theater als moralischer

Anstalt sehr nahe stand, wollte er doch keineswegs als

"Klassiker" verstanden werden, denn die Klassiker waren

Vertreter des Bthrgertums. Klassisch $z u$ schreiben, meint Brecht, ist "der Versuch, bestimmte Vorschlage ethischer und asthetischer Art dauerhaft zu gestalten und ihnen etwas 
Endgthltiges, Abschliessendes zu verleihen" und ist damit "der Versuch einer Klasse, sich Dauer und ihren Vorschlagen den Anschein von Endgttltigkeit zu geben." 4

Kathe Rllicke sieht im epischen Theater vor allem die Verschiebung des Lehrziels. Whhrend Schiller daraufhinarbeitete, in den Zuschauern ein Glucksgefthl darthber zu erwecken, ein Mensch unter anderen Menschen zu sein, wollte Brecht spezifische Misstünde aufzeigen und abschaffen. Weiter verlangte er das Element des Genusses bei der Betrachtung eines Schauspiels, allerdings nicht den aristotelisch-klassischen Genuss in der Selbstaufgabe und Katharsis, sondern den Genuss des Lernens.

Kathe Rulicke bemerkte zu diesen zwei Punkten:

Brecht erkannte, dass das Theater nur dann einer neuen gesellschaftlichen Funktion zugefthrt werden kann, wenn es die politisch-gesellschaftlichen Interessen seines Publikums bedient. Zugleich wurde ihm klar, dass die Trennung von Belehrung und Unterhaltung in der Klassengesellschaft ihre Ursache hatte, dass sie eine Erscheinung des Spatkapitalismus ist. Wahrend das Arbeiterpublikum die Lehren der "Mutter" als Unterhaltung genoss, griffen die bourgeoisen Kritiker den Lehrcharakter des Stlickes an und stellten die Begriffe "lehrreich" und "unterhaltsam" als einander ausschliessend gegentiber. Brecht schrieb dazu: "Dieser Trennung nachzugehen ist nicht ohne Reiz. Es mag tberraschen, dass hier eine Degradierung des Lernens schlechthin beabsichtigt ist, indem es nicht als Genuss vorgestellt wird. In wirklichkeit wird natturlich der Genuss, indem er so sorgfaltig von jedem Lehrwert entleert wird, degradiert. Aber man braucht sich nur umzusehen, welche Funktion das Lernen in der burgerlichen Gesellschaftsordnung hat. Es funktioniert als Einkauf von materiell verwertbaren Kenntnissen... Zugeben, dass ich etwas, was $z u$ meinem Fach gehort, noch nicht kann, also mich beim Lernen ertappen lassen, ist gleichbedeutend mit eingestehen, dass ich nicht konkurrenzfuhig bin und keinen kredit beanspruchen darf...5 
Whhrend der frthe Schiller sein Publikum mitreissen wollte, suchten sowohl Brecht als auch der spate Schiller Distanz zwischen dem Vorgang auf der Bthne und dem Publikum. In der Braut von Messina greift der Chor "verfremdend" ein; er sollte Ruhe in die Handlung bringen.

Das Gemuth des Zuschauers soll auch in der heftigsten Passion seine Freiheit behalten; es soll kein Raub der Eindrttcke seyn, sondern sich immer klar und heiter von den Rthrungen scheiden, die er erleidet... Wenn die Schlage, womit die Tragodie unser Herz trifft, ohne Unterbrechung aufeinander folgten, so whrde das Leiden thber die Thatigkeit (!) siegen. Wir wlirden uns mit dem Stoffe vermengen und nicht mehr ther demselben schweben. Dadurch, dass der Chor die Teile auseinanderhalt und zwischen die Passionen mit seiner beruhigenden Betrachtung tritt, gibt er uns unsere Freiheit zurthck, die im Sturm der Affekte verloren gehen wirde. 6

Die Ubereinstimmung dieser Ansicht Schillers mit der Brechts ist erstaunlich.

In der Charakterdarstellung des Klassikers und des Sttlckeschreibers allerdings finden wir fundamentale Unterschiede. In einer Selbstbesprechung seiner "Rüuber" sagte der junge Schiller folgendes ther seinen Franz:

Einen heuchlerischen, heimttlckischen Schleicher wird man entlarvt erblicken... Sonst ist dieser Charakter, so sehr er mit der menschlichen Natur misstimmt, ganz tbereinstimmend mit sich selbst... (sibi constans!)... Dieser Charakter ist ein eigenes Universum...

In Bezug auf Karl heisst es dann:

Noch ware ein Wort thber die zweideutige Katastrophe der ganzen Liebesgeschichte zu sagen. Man fragt, war es tragisch, dass der Liebhaber das Madchen ermordet? War es in dem gegebenen Falle naturlich? War es notwendig? War kein minder schrecklicher Ausgang mehr tubrig?

Ich will auf das letzte zuerst antworten: 
Nein! Möglich war keine Vereinigung mehr, unnattirlich und hochst undramatisch wäre eine Resignation gewesen. Zwar vielleicht diese letzte möglich und schon auf Seiten de's männlichen Raubers - aber wie ausserst widrig auf Seiten des Maddchens!

Offenbar krönt diese Wendung das ganze stthck und vollendet den Charakter des Liebhabers und Răubers.7

Hat der Dramatiker also seinen Figuren ein bestimmtes Format gegeben, hat er sie mit gewissen Zthgen angelegt, dann folgt die Handlung unausweichlich. (Ein Vergleich mit Brechts Behandlung der untreuen Freundin im Trommeln in der Nacht zeigt, dass fur Brecht unter ahnlichen Umständen eine Wiedervereinigung der Liebhaber durchaus möglich war.)

Schillers Stucke sind vor allem vom Ende her konzipiert. Nur von da her erkennt der Zuschauer die moralische Grösse der hier behandelten Idee. Bei Brecht dagegen liegt die Betonung auf dem Handlungsverlauf; die Anlage seiner Figuren in ihren widersprtuchlichkeiten fordert keine unausbleibliche Katastrophe, sondern erlaubt oft einen mehr oder weniger konstruktiven Kompromiss, wie zum Beispiel im Fall Galileis. In diesem Sinn konstatiert auch Jendreieck:

Grusche... ist nicht einfach Charakter, der eben so handeln muss und nicht anders handeln kann, sondern gerat in ihre Rolle durch die ther sie hereinbrechenden Ereignisse, reagiert auf die Welt und agiert darum gestisch. Sie kann gerade deshalb durchkommen, weil sie in ihrem Verhalten nicht durch einen unveranderlichen Charakter determiniert ist. 8

Diese Gabe, sich nach den Verhaltnissen zu richten, besassen die traditionellen Dramenhelden nicht. Brecht kommentiert:

Odipus, der sich gegen einige Prinzipien, welche 
die Gesellschaft der Zeit stutzten, versundigt hat, wird hingerichtet, die Gutter sorgen daftr, sie sind nicht kritisierbar. Die grossen Einzelnen des Shakespeare, welche die sterne ihres schicksals in der Brust tragen, vollfthren ihre vergeblichen und todlichen Amoklaufe unaufhaltsam, sie bringen sich selbst zur Strecke... die Katastrophe ist nicht kritisierbar. Menschenopfer allerwege! 9

Wahrend Brechts "Theater als moralische Anstalt" also klassische Zthge aufweist, oder Brecht sich doch in der Nachfolge Schillers sieht, hat er im Aufbau seiner Figuren mit der Tradition gebrochen. Es galt ja nicht, eine edle Idee zu feiern, sondern gesellschaftliche Missstände abzuschaffen. 
KAPITEL IV

\begin{abstract}
REALISMUS IN DER DARSTELLUNG: DER GENAU BEOBACHTENDE BLICK UND PHILOSOPHISCH-WISSENSCHAFTLICHE SYSTEME

ALS GRUNDLAGE FUR DEN CHARAKTERAUFBAU
\end{abstract}

Da bei Brecht das Gedankliche (der ideelle Gehalt)

und das Visuelle (die Darstellung) immer eine Einheit waren, fthlte er sich den darstellenden Kthnstlern wie den Bildhauern nahe verwandt. Das Sehen tuberhaupt, und dann das "richtige" Sehen fthren erst zur realistischen Darstellung des Menschen. Die folgenden Absätze beschreiben, wie die neue Optik von alten Konzepten wegfthrt und zu neuer Darstellung zwingt.

Man muss wissen, dass die Bildhauer lange Zeit ihre Aufgabe darin sahen, das "Wesentliche, Ewige, Endgthltige," kurz "die Seele" ihrer Modelle zu gestalten. Ihre Vorstellung war die: Jeder Mensch hat einen ganz bestimmten Charakter, den er mit auf die Welt bringt und den man beim Kind schon beobachten kann. Dieser Charakter kann sich entwickeln, das heisst, er wird sozusagen immer bestimmter, je alter der Mensch wird, er kommt immer mehr heraus, der Mensch wird sozusagen immer deutlicher, je länger er lebt. Nattirlich kann er auch undeutlicher werden, kann er zu einem bestimmten Zeitpunkt, sei es in der Jugend, sei es in der Zeit der Reife, am allerdeutlichsten und starksten ausgeprägt sein und sich dann wieder verwischen, verschwimmen, verfluchtigen. Es ist aber immer etwas ganz Bestimmtes, was sich da herausbildet, verstarkt oder verfluchtigt, eben die ganz besondere, ewige, einmalige Seele dieses besonderen Menschen. Der Kunstler muss nun diesen Grundzug, dieses entscheidende Merkmal des Individuums herausarbeiten, alle andern Zutge bei ein und demselben Menschen ausmerzen, so dass eine klare Harmonie entsteht, die der Kopf selber in Wirklichkeit nicht bieten mag, die aber das Kunstwerk, die kthstlerische Abbildung 
bietet.

Diese Auffassung von der Aufgabe des Kthnstlers scheint nun von einigen Kunstlern aufgegeben zu werden, und an ihre stelle tritt eine neue Auffassung. Diese Bildhauer sind sich natturlich auch klar dartber, dass es beim Individuum so etwas wie einen ganz bestimmten charakter gibt, durch den es sich von andern Individuen unterscheidet. Aber diesen Charakter sehen sie nicht als etwas Harmonisches, sondern als etwas widerspruchsvolles, und sie erblicken ihre Aufgabe nicht darin, die Widersprthche in einem Gesicht auszumerzen, sondern sie zu gestalten. Fur sie ist ein menschliches Antlitz ungefăhr wie ein Schlachtfeld, auf dem gegnerische Mächte miteinander einen ewigen Kampf ausfechten, einen Kampf ohne Entscheidung... Das Portrait stellt nicht eine Endrechnung, einen Saldo dar, das, was nach all den Gewinnen und Verlusten tubrigbleibt; sondern es erfasst das menschliche Antlitz als etwas Lebendes, Weiterlebendes, in Entwicklung Begriffenes. Nicht als ob dadurch nicht Harmonie entstunde! Die einander bekämpfenden Krăfte halten sich schliesslich die Waage... Es ist eine Harmonie, aber es ist eine neue Harmonie.

Diese neue Betrachtungsweise der Bildhauer stellt zweifellos einen Fortschritt in der Kunst der Betrachtung dar, und das Publikum wird einige Zeit lang einige Schwierigkeiten haben, wenn es ihre Kunstwerke betrachtet bis auch das publikum diesen Fortschritt gemacht haben wird. I

Bildhauer und Dramaturg gehen also dem Publikum voraus und mtissen damit rechnen, wenigstens eine zeitlang missverstanden zu werden. Ist in den Figuren kein klares Schema zu entdecken, fthlt sich der Zuschauer unsicher. Er versteht zunăchst nicht, was der stuckeschreiber von ihm will, war doch traditionell der Charakter des Helden der Haupttrăger der ideologischen Botschaft des Autors. Er sieht nur das Rutsel, das Chaos. Dagegen verwehrt sich Brecht:

Jedenfalls bin ich nicht so abschreckend chaotisch, wie man zuweilen glaubt. Ich beschränke mich zwar in meinen Dramen auf den reinen Stoff, aber ich gestalte nur das Typische, ich wahle aus - 
das ist die Ordnung. Auch wenn sich eine meiner Personen in widersprtichen bewegt, so nur darum weil der Mensch in zwei ungleichen Augenblicken niemals der gleiche sein kann. Das wechselnde Aussen veranlasst ihn beständig zu einer inneren Umgruppierung. Das kontinuierliche Ich ist eine Mythe. Der Mensch ist ein immerwahrend zerfallendes und neu sich bildendes Atom. Es gilt zu gestalten, was ist. ${ }^{2}$

Brecht fthlte, dass "was ist," die Wirklichkeit, absichtlich vom burgerlichen Theater ignoriert worden war. Rthlicke Weiler zitiert einen weiteren Ausspruch Brechts, der nun die Anwendung seiner Theorien betreffend Charakter auf das neue Theater darlegt:

Die Darstellungen des burgerlichen Theaters gehen immer auf die Verschmierung der widersprthche, auf die Vortüuschung von Harmonie, auf die Idealisierung aus. Die Zustände werden dargestellt als so, wie sie gar nicht anders sein konnen; die Charaktere als Individualitäten, nach dem Wortsinn Unteilbarkeiten von Natur aus, "aus einem Guss," als sich beweisend in den verschiedensten Situationen, eigentlich auch ohne alle Situationen bestehend. Wo es Entwicklung gibt, ist sie nur stetig, niemals sprunghaft, und immer sind es Entwicklungen in einem ganz bestimmten Rahmen, der niemals gesprengt werden kann.

Das entspricht nicht der wirklichkeit und muss von einem realistischen Theater aufgegeben werden. 3

Brecht beschaftigte sich also mit der obersetzung des Gedanklichen ins Visuelle, und umgekehrt mit dem ideellen Inhalt, den das visuelle zu bieten hatte.

Das Symbol fur die gesamte Gestalt-Psychologie ist der berthmte Scherenschnitt von den zwei schwarzen Profilen, die einander zugekehrt sind, oder der dazwischen weiss ausgesparten Vase. Es bedarf einer geistigen Umstellung des Beschauers, nach der zuerst entdeckten nun auch die zweite Figur plastisch zu sehen. Diese absichtliche innere 
Umstellung, das neue Sehen, will Brecht nun lehren.

Das lange nicht Geänderte nämlich scheint unanderbar. Allenthalben treffen wir auf etwas, das zu selbstverstandlich ist, als dass wir uns bemthen mussten, es zu verstehen. Was sie miteinander erleben, scheint den Menschen das gegebene menschliche Erleben. Das Kind, lebend in der Welt der Greise, lernt, wie es dort zugeht. wie die Dinge eben laufen, so werden sie ihm gelaufig. Ist einer kthn genug, etwas nebenhinaus zu wtinschen, winschte er es'sich nur als Ausnahme. Selbst wenn er, was die "Vorsehung" tuber ihn verhangt, als das erkennte, was die Gesellschaft fur ihn vorgesehen hat, musste ihm die Gesellschaft, diese malchtige Sammlung von Wesen seinesgleichen, wie ein Ganzes, das grosser ist als die Summe seiner Teile, ganz unbeeinflussbar vorkommen - und dennoch wäre das Unbeeinflussbare ihm vertraut, und wer misstraut dem, was ihm vertraut ist? Damit all dies viele Gegebene ihm, als ebensoviel Zweifelhaftes erscheinen könnte, musste er jenen fremden Blick entwickeln, mit dem der grosse Galilei einen ins Pendeln gekommenen Kronleuchter betrachtete. Den verwunderten diese Schwingungen, als hatte er sie so nicht erwartet und verstunde es nicht von ihnen, wodurch er dann auf die Gesetzmăssigkeiten kam. Diesen Blick, so schwierig wie produktiv, muss das Theater mit seinen Abbildungen des menschlichen Zusammenlebens provozieren. 4

Der objektive Blick des Wissenschaftlers kann der

eines Psychologen sein oder der eines Anthropologen. So

heisst es im Messingkauf:

Wer mit Erstaunen die Essitten, die Gerichtspflege, das Liebesleben wilder volkerschaften betrachtet hat, der wird auch unsere Essitten, unsere Gerichtspflege und unser Liebesleben mit Erstaunen betrachten können. Der armselige spiessbthrger findet in der Geschichte immer nur die gleichen Triebfedern vor, die seinen. Und die nur, soweit er sie kennt, also nicht sehr weit. Der Mensch trinkt nachmittags Kaffee, ist eifersthchtig auf seine Frau, will in der Welt vorwartskommen, und das tut er nur mehr oder weniger und besser weniger. "Der Mensch andert sich nicht," sagt er, und wenn er auch seiner Frau unangenehmer ist, als er ihr vor 20 Jahren war, so waren eben alle Menschen mit 45 Jahren ihren Frauen unangenehmer als mit 25 
Jahren... Er ändert sich nur wie der Bachkiesel, der von den andern Bachkieseln abgeschliffen wird. Und wie der Bachkiesel bewegt er sich vorwarts. $\mathrm{Da}$ er kein ziel verfolgt, könnte er eigentlich alles tun, 'unter Umstanden' zum Beispiel auch die Welt erobern wie Casar... Er ist durchaus wie jedermann, jedermann ist wie er. Unterschiede sind ihm nicht wesentlich, es ist ihm alles eins. In allen Menschen sieht er den Menschen, er, der nur ein Singular des plurals Menschen ist. So steckt er mit seiner geistigen Armut alles an, womit er geistig in Berthrung kommt...5

Nehmen wir also diese Individuen der modernen Gesellschaft unter die Lupe und betrachten wir sie mit wissenschaftlichem Detachement so finden wir vollige sterilitat des Verhaltens. Der "Spiessburger" versteckt sich hinter dem "allgemein-Menschlichen," er verfolgt selber kein Ziel was ihm theoretisch alle Moglichkeiten offen lässt, und wie ein Bachkiesel wird er geschliffen und geschoben. Er ist, sozial gesehen, vollig unproduktiv.

Wenn solches Verhalten naturlich scheint, so muss es jetzt auffullig gemacht werden. Das epische Theater sieht in der Beleuchtung solcher Sitten seinen Zweck. Brecht fasst die Aufgaben und Begrenzungen seines Theaters so zusammen:

Das epische Theater ist hauptsächlich interessiert an dem Verhalten der Menschen zueinander, weil es sozialhistorisch bedeutend (typisch) ist. Es arbeitet Szenen heraus, in denen Menschen sich so verhalten, dass die sozialen Gesetze, unter denen sie stehen, sichtbar werden. Dabei mussen praktikable Definitionen gefunden werden, das heisst, solche Definitionen der interessierenden Prozesse, durch deren Benutzung in diese Prozesse eingegriffen werden kann. Das Interesse des epischen Theaters ist also ein eminent praktisches. Das menschliche Verhalten wird als verunderlich gezeigt, der Mensch als abhängig von gewissen 8konomisch-politischen Verhaltnissen 
und zugleich als fuhig, sie zu verandern. ${ }^{6}$

Im Messingkauf, heisst es weiter:

Unsere neue Aufgabe erfordert, dass wir, was zwischen Menschen vorgeht, in aller Breite, Widersprthchlichkeit, in dem Zustand der Losbarkeit oder Unlosbarkeit vorlegen. Es gibt nichts, was nicht zur: Sache der Gesellschaft gehort. Die klar bestimmten, beherrschbaren Elemente haben wir vorzufthren in ihrer Beziehung zu den unklaren, unbeherrschbaren, so dass also auch diese in unserm Thaeter (sic) vorkommen.7

Im neuen Theater, 'Thaeter' genannt, liegt der Schwerpunkt also nicht mehr auf dem Individuum und seinen Konflikten sondern auf den sozial-strategischen Handlungen zwischen Menschen. (Kohlhase bemerkt, dass in der neuen Optik Brechts die kleinste Einheit der Gesellschaft nicht mehr der einzelne Mensch ist, sondern zwei Menschen sind. ${ }^{8}$ Diese Handlungen zwischen Menschen also sollen so dargestellt werden, dass das dahinterliegende Gerthst sozialer Umstände sichtbar wird. Ob die dargestellten Handlungen zu einer Losung auf der Bthne fthren oder nicht, ist unwichtig. Sie werden in dem Zustand der "Lösbarkeit oder Unlobsbarkeit" vorgelegt. An diesem Punkt thergibt der Stthckeschreiber das Problem dem Zuschauer. Es ist nun an ihm, an einer Losung weiterzuarbeiten.

Der neue Realismus der Anschauung und Darstellung war schon von Karl Marx angebahnt worden. In seinen Frthschriften verlangt er folgendes:

Es wird nicht ausgegangen von dem, was die Menschen sagen, sich einbilden, sich vorstellen, auch nicht von den gesagten, gedachten, eingebildeten, vorgesteliten Menschen, um davon aus bei den leibhaftigen Menschen anzukommen; es 
wird von den wirklich tatigen Menschen ausgegangen und aus ihrem wirklichen Lebensprozess auch die Entwicklung der ideologischen Reflexe und Echos dieses Lebensprozesses dargestellt.9

Brecht empfand die herkommliche Charakterdarstellung als schematisch, schablonenhaft und unrealistisch, da sie zu sehr auf Spekulation und Tradition aufgebaut war. Um so mehr sagte ihm eine neue Beobachtungsmethode $\mathrm{zu}$, die willens war, alles zu dokumentieren. Diese neue Beobachtungsmethode war der Behaviorismus.

Der Amerikaner Watson, Vater der Verhaltensforschung und der modernen Reklame, der 1913 zum ersten Mal mit seinen neuen Begriffen vor die offentlichkeit trat, definierte die Essenz des Menschen wie folgt: "Personality is the sum of activities that can be discovered by actual observation of behavior over a long enough time to give reliable information." 10

Watsons wichtigste Termini sind "prediction" und "control." Hat man genthgend harte Daten, kann man das Verhalten des Menschen voraussagen und daher auch kontrollieren. Watson vergleicht den Menschen mit einem Boomerang, der unter gewissen physikalischen Gesetzen steht. Nur eine Anderung dieser körperlichen Umstände kann eine Veränderung in der Flugbahn des Boomerangs herbeifthren.

In dhnlicher Weise sieht Brecht das Individuum in einer Reflexsituation zu den Stimuli der Umwelt, den ausseren situationen, auf die es reagiert. Er betont das Verhalten im Gegensatz zum Sein. Das Denken soll nicht der 
Anlass zur Handlung sein, sondern auf die Handlung soll das Denken folgen. In einem Interview, das Brecht 1934 der Kopenhagener Zeitung "Extrabladet" gab, sagte er:

Alle Wissenschaften haben in unserer Zeit eine reissende Entwicklung durchgemacht. Wir haben eine ganz neue Psychologie bekommen - man denke nur an des amerikanischen Dr. Watsons 'Behaviorismus.' Wo andere Psychologen introspektive seelische Tiefenforschung vorschlugen, wo sie das menschliche Wesen drehten und wendeten, da grtundet sich diese Philosophie ausschliesslich auf die nach aussen tretenden wirkungen der menschlichen Psyche - das Verhalten des Menschen. ${ }^{1}$

Was Brecht von Watson trennt ist die Bedeutung, die er den sozialen Umständen beimisst. Er sieht die Menschen in ihren Beziehungen zueinander unter dem Uberbau der burgerlichen Institutionen wie Ehe, Geld, Krieg, Justiz, etc. Je nach dem Stoffkomplex sieht Brecht ganz neue Beziehungen zwischen den Menschen. Hier greift Marx ein, denn der Marxismus lehrt, dass der Charakter der Produktionsmittel die gesellschaftlichen Verhaltnisse bestimmt, indem er die wirtschaftlichen Grundlagen und Mangelzustande schafft.

Watsons Reflexe sind biologisch, Brechts Reflexe sind sozial. In beiden fallen jedoch wird die Umwelt sowohl als auch das Individuum als veränderbar gesehen.

Sokel sieht dieses allmahliche Abweichen von watsons Prinzipien als ein Resultat der Reife Brechts und seiner Beschäfigung mit dem Marxismus. Er sieht den Behaviorismus aber als weiterbestehendes Element in Brechts Werken:

It would be over-simplifying to assert... that the early Brecht's behaviorism was supplanted by the mature Brecht's marxism. In as far as we mean by behaviorism in dramaturgy the reduction 
of the character to his gestic activity, even the Marxist Brecht remains behavioristic. But the behavioristically seen gesture, the character's fundamental stance, is enriched by the dimension of social strategy. The figure now is not only activity; it is the sum total of its socially strategic actions.12

In der folgenden Auswahl bewertet Brecht selbst die herkömmliche Psychologie und die neue Technik der Menschenbetrachtung wobei der Blickpunkt immer der der Nutzlichkeit ist.

Die wenigsten unserer "Realisten" haben zum Beispiel Kenntnis genommen von der Entwicklung der Auffassungen ther die menschliche Psyche in der zeitgenossischen Wissenschaft und Praxis. Sie halten immer noch bei einer Psychologie introspektiver Art, einer Psychologie ohne Experimente, einer Psychologie ohne Historie und so weiter. Nicht, dass ihre Menschenbeschreibungen fur den Psychologen ohne Interesse sind, aber um daraus Nutzen (Menschenkenntnis) zu schopfen, muss man eben ein Psychologe sein...

Diese Leute beschreiben sich selber und nichts als sich selber. Um zu ihren Aussagen tuber die Menschen zu kommen, unterwerfen sie sich selber, jeder sein eigenes Versuchstier, imaginăren Experimenten. Da sie alles zu tun bereit sind, um die Einfthlung des Lesers in ihre Figuren zu erzwingen, vom Gelingen welcher Operation ihnen der ganze Kunstwert ihrer Arbeiten abzuhangen scheint, engen sie die jeweils zu beschreibende Figur so ein, dass eine Einfthlung "jedes" Lesers moglich sein muss. Nicht nur durch die Klassen, auch durch die Jahrhunderte gleichen sich ihre Menschen, so dass sie keinerlei schichtungen in sich haben noch echte widersprtlche...

Diese Technik der Menschenbetrachtung und Darstellung ist vollig primitiv, und die Menschenkenntnis der schriftsteller ist denn auch jedem erkennbar infantil: Man könnte mit ihr noch kein Auto verkaufen. Die Primitivitut ihrer Figuren, ihre Armut an Reaktionen, Schablonenhaftigkeit, Entwicklungslosigkeit zwänge sie allein schon zu Einschränkungen bei all und jedem... sämtliche Prozesse verlaufen durftig und schematisch. Uberall ersetzen Nuancen und Abnormitaten wirklichen Reichtum.

Wir bekommen bei diesen Autoren sehr verwickelte 
seelische Konstellationen vorgesetzt, nur ist weit und breit keine Kausalitat zu entdecken, es sind von der Umwelt abgetrennte Psychen. Wir begegnen auch komplizierten Verlaufen, nur schnurren auch sie ohne Ursachen ab. Hier ist hochentwickelte, aber unfruchtbare Technik.13

\section{Und weiter auf Seite 198:}

Eine realistische Handlungsweise ist eine solche, welche die treibenden Krafte in Bewegung setzt... Der Beweggrund des Handelns einer Roman-oder Sttlckfigur ist dann realistisch angegeben, wenn ein anderer Beweggrund ein anderes Handeln ergeben hatte und kein anderer dasselbe. Es ist realistisch, die Ursachen von Prozessen in die Reichweite der Beeinflussbarkeit durch die Gesellschaft zu stossen. 14

Und auf Seite 199 abschliessend:

Die Realisten bekümpfen jede Art von Schematismus $\mathrm{da}^{\mathrm{d}}$ er die Realität nicht beherrschbar macht. 15

Fthr Brecht muss also der Hauptzweck aller Psychologie sein, die wirklichkeit beherrschbar zu machen, "ein Auto damit verkaufen zu können." Watson, der vater der modernen Reklame, hätte hierin mit ihm thbereingestimmt.

Obwohl Brecht Freuds Werke studierte und auch einiges davon verarbeitete ${ }^{16}$ lehnte er die Psychoanalyse als werkzeug der Menschenkenntnis prinzipiell ab. Was war doch die Psychoanalyse anderes als das Aufdecken bewusster oder verdrängter Erinnerungen? Um aber den Menschen und die Welt veränderbar zu machen, musste seine Herkunft fur nichts gelten. Hic Rhodos, hic salta, war seine Losung. Was der Mensch war, ist belanglos. Nur was er jetzt tut, ist fur die Zukunft bedeutsam.

In einem seiner Exilgedichte schrieb er: 
Einst dachte ich: in fernen Zeiten

Wird mein Name noch genannt werden Mit anderen

Aber heute

Bin ich einverstanden, dass er vergessen wird Warum soll es eine vergangenheit geben, wenn es eine Zukunft gibt?17 
KAPITEL V

DIE UMWEIT ALS ERZATZ FUR DEN CHARAKTER, ALS ANSPORN FUR DIE HANDLUNG

Vom Zuschauer wird erwartet, dass er die Handlungen der Menschen, im Leben sowohl als auch auf der Bthne, genau und im Detail registriert und sich von begrifflichen burgerlichen Vorurteilen in Bezug auf die Motivierung dieser Handlungen freihalt. Schliesslich erhebt sich aber dennoch die Frage nach dem Warum. Wenn der Mensch keine festen Charaktereigenschaften besitzt, die ihn dazu drüngen, so oder so zu handeln, wo sind dann die Ursachen seiner Verhaltungsweise zu finden?

Im Messingkauf weist Brecht darauf hin, dass wir uns selber oft tber die Triebkrafte, die unsere Handlungen bestimmen, im Unklaren sind. Auch hier mussen wir den wissenschaftlichen Blick uben. Brecht fasst das so zusammen:

Wir alle haben sehr unklare Vorstellungen davon, wie unsere Handlungen sich auswirken, ja wir wissen nur selten, warum wir sie unternehmen. Die Wissenschaft tut wenig, um die Vorurteile auf diesem Gebiet zu bekämpfen. Als Hauptmotive werden immer wieder so fragwthrdige genannt wie Habsucht, Ehrgeiz, Zorn, Eifersucht, Feigheit und so weiter. Blicken wir auf Geschehenes zurtuck, so glauben wir Berechnungen feststellen zu können, gewisse Urteile ther unsere Lage damals, Pläne, Wahrnehmungen von Hindernissen, die ausser unserem Machtbereich standen. Aber wir haben diese Berechnungen gar nicht angestellt, wir schliessen nur aus unserm damaligen Handeln auf solche Berechnungen. Unsere Abhungigkeit auf allen Seiten in allen Entscheidungen ist uns nur dumpf fthlbar. Irgendwie hängt alles zusammen, 
fthlen wir, aber wie, wissen wir nicht. So erfuhrt die Menge den Brotpreis, die Kriegserklürung, den Mangel an Arbeit wie Naturereignisse, Erdbeben oder Uberschwemmungen.1

Es sind also äussere Umstande, die unser Leben bestimmen, aber wir erkennen nicht, das sie veränderbar sind. Wir nehmen gottergeben unser "Kreuz" auf uns und unterscheiden nicht zwischen losbaren und unlosbaren Problemen. Der Krieg zum Beispiel ist kein Akt Gottes, keine Naturkatastrophe. Er ist ein von der Gesellschaft herbeigefthrtes Ereignis und kann daher verhindert werden. Diese Einsicht mangelt noch vielen Menschen, meint Brecht.

Brecht formuliert diesen Gedanken wie folgt:

Auch unsere soziale Umwelt betrachten wir als ein Sttlck Natur, fast als Landschaft. Das Geld, das Zins bringt, sehen wir an wie den Birnbaum, der Birnen bringt. Die Kriege, welche uthnliche Wirkungen haben und so unvermeidlich erscheinen wie Erdbeben, sehen wir eben dann auch an wie Erdbeben. Sehen wir so etwas an wie die Ehe so sagen wir: Das ist das Natürliche. Mit Erstaunen horren wir, dass an anderen Orten und an unserem Ort $z u$ anderen Zeiten andere Verbindungen von Mann und Weib als die natturlichen angesehen wurden.2

Statt eines charakterfesten Helden, der dem drauenden Schicksal die Stirne bietet, sieht Brecht einen fast kindlich unbewussten Menschen, in einer historisch sich von Tag zu Tag verändernden Welt. Der Mensch fthlt dumpf seine Abhängigkeit von den ihn umgebenden Umständen; er muss lernen, sie klar zu erkennen und die ihm feindlichen gesellschaftlichen Krafte zu identifizieren. Es ist Aufgabe der Bthne, ihm dabei zu helfen. Das ist ein Prozess, den man heute als consciousness raising bezeichnen könnte. 
Brecht meint im Messingkauf:

Nicht dass man nicht alle Glieder der kette sieht, ist schlimm, sondern dass man die Kette nicht sieht. Wir haben dartuber geklagt, dass wir die Gegner so schwer auf ein und dieselbe Bthne bringen können. Wenngleich hier vermittels einer neuen Technik viel geschehen kann, so kommt es doch hauptsächlich darauf an, dass es nicht so scheint, als gübe es keine solchen Gegner. Oft schiebt der Dramaturg, wenn er den Gegner nicht sieht oder nicht sichtbar machen kann, irgend etwas anderes vor, was "nuherliegt." und den Vorgang einigermassen begrtindet. Charakterzlige seiner Helden, besondere Ungunst gerade seiner Verhaltnisse und so weiter. Und luckenlos fugt er dann seine Motivierungen, wahrend in wirklichkeit, da ja die bewegenden Ursachen ausserhalb wirken, Wendungen erfolgen missten, die aus dem vorne gegebenen Material nicht erklärbar sind. 3

Da das traditionelle Drama lthckenlos sein soll, wird der Charakter des Helden als Leitfaden genommen, als Schnthrchen, an dem alles ablauft. Brecht als realistischer Kthnstler aber erkennt, dass der Mensch eine Variable des Milieus ist und das Milieu eine Variable des Menschen, das bedeutet, dass das Milieu in Beziehungen zwischen Menschen aufgelost werden muss. Nur so werden die Glieder der Kette erkennbar.

Hier schliesst sich also der circulus vitiosus, wie Brecht ihn sieht. Wenn der blurgerliche Dramaturg in der Konstruktion seines Dramas an dem Punkt anlangt, wo er endlich die dem Menschen feindlichen Umstände anprangern mlisste, greift er auf die Motivierung durch den Charakter des Helden zurluck. Das geschieht erstens aus Faulheit oder Unvermögen, weil es oft zu schwierig ist, den Gegner, numlich die zeitgenössische Gesellschaft, auf die Bthne zu bringen. 
Zweitens wlurde der Einfluss von ausserhalb des eng umschriebenen kreises des stllaks "unlogische," das heisst unerwartete Winkelztuge in die Handlung bringen, was traditionell unbedingt $\mathrm{zu}$ vermeiden ist. Vollkommen ignorieren allerdings konnte auch der burgerliche schriftsteller die Umwelt nicht, jedoch sie funktionierte. nur als setting, als Kolorit. Dazu heisst es im Messingkauf:

Diese Umwelt war naturlich auch im bisherigen Drama gezeigt worden, jedoch nicht als selbstandiges Element, sondern nur von der Mittelpunktsfigur des Dramas aus. Sie erstand aus der Reaktion des Helden auf sie. Sie wurde gesehen wie der Sturm gesehen werden kann, wenn man auf einer Wasserflache die Schiffe ihre Segel entfalten und die Segel sich biegen sieht. Im epischen Theater sollte sie aber nun selbständig in Erscheinung treten. 4

Nur indem die Umwelt also als vollgthltiger Partner im dramatischen Geschehen erscheint und die Idee des Charakters ersetzt wird durch die Wechselwirkungen zwischen Menschen und Milieu, kann eine Denkweise eingefuhrt werden, die Hoffnung auf positive Anderungen in der Zukunft zulasst.

Kohlhase betont die studierhaltung des sttickeschreibers seinen Figuren gegentber, das Unfertige in ihnen und die Rolle, die der von aussen eingreifende Zufall in der Entwicklung dieser Figuren spielt. Da ihre Reaktionen unvorhersehbar sind, entsteht eine Krise nach der anderen. Statt auf einen Hohepunkt zuzusteuern, befindet sich das stuck in einer permanenten Peripetie. 5 Geissler weist darauf hin, dass die Kritik und Interpretation solcher Figuren sehr schwierig wird:

Jeder Versuch, in den Personen die Einheit eines Charakters $z u$ erkennen fuhrt zu Fehldeutungen. 
Die Widersprtiche mussen klar und unvereinbar deutlich bleiben. Der Widerruf Galileis lasst sich im Brecht'schen Sinn erst dann ganz verstehen, wenn man darauf verzichtet, ihn als charakterliches Versagen und Verrat zu verstehen... Er grtindet vielmehr in dem Widerspruch von bequem-gentsslicher sinnlichkeit, die am Leben hangt, und wissenschaftlichem Forschungstrieb...6 6

Die Reaktionen Galileis auf die Forderungen der Umwelt werden also einmal so, einmal so ausfallen. Geissler kann daher keinerlei vorbildhafte zthge in den Figuren Brechts finden. Sie regen nicht zur Nachahmung an, sondern zum Nachdenken. Das Nachdenken aber ist eine Tätigkeit, die zur Veränderung der Haltung fthrt und dadurch zum richtigen Verhalten in der Zukunft. 


\section{KAPITEL VI}

DER EPISCHE CHARAKTER ALS LEHR- UND STILMITTEL

Wo Brechts Kunstlertum gegen seine politische Lehrtätigkeit abzugrenzen ist, ist eine ungeloste streitfrage. In gleicher Weise sind seine Technik und seine politischhumanistische Uberzeugung Teil seiner schopferischen Tatigkeit. Der Charakterbegriff, der in seiner Veränderlichkeit ein zentrales Thema Brechts darstellt, lasst sich daher auch von verschiedenen seiten beleuchten.

Grundsatzlich bewegte Brecht die Sorge, dass ein allzu logisch und routiniert konstruiertes Charakterbild des Helden den Zuschauer dazu verleiten könnte, auszurufen: "Ja naturlich, so ist das," und damit das dargestellte Problem ad acta $\mathrm{zu}$ legen. So zeigte er denn immer wieder die Veranderlichkeit des menschlichen Charakters, einerseits weil er es für "realistisch" hielt, andererseits um den Zuschauer vom voreiligen Klassifizieren abzuhalten. Der epische Charakter war also ein wesentlicher Aspekt der Brechtschen Verfremdungstechnik. Einer der Wahlsprthche, nach denen Brecht selbst lebte, war Hegels "Sein ist Werden." In seinem Buch tober Klassiker zitiert er Hegel wie folgt:

Alles, was ist, ist nur dadurch, dass es auch nicht ist, d. h. dadurch, dass es wird oder vergeht.

Im Werden ist Sein und Nichtsein, ebenso im Vergehen. Das Werden geht tuber in ein Vergehen 
und das Vergehen in ein Werden. Aus dem vergehenden Ding wird ein anderes Ding, in dem werdenden Ding vergeht ein anderes. So ist keine Ruhe in den Dingen, noch im Betrachtenden... Meister Hegel sagte: Dinge sind Vorkommnisse, Zustände sind Prozesse, Vorgänge sind Ubergänge. I

Diese neue Auffassung des Menschen liess sich, wie Brecht in den Anmerkungen zur Dreigroschenoper betonte, nur in epischer Form ausdrtlcken, denn

heute, so das menschliche Wesen als das Ensemble aller gesellschaftlichen Verhaltnisse aufgefasst werden muss, ist die epische Form die einzige, die jene Prozesse fassen kann, welche einer Dramatik als Stoff eines umfassenden Weltbildes dienen. Auch der Mensch, und zwar der fleischliche Mensch, ist nur mehr aus den Prozessen, in denen er und durch die er steht, erfassbar. 2

Die Auffassung des Menschen im burgerlichen Theater war "geschichtslos," denn sie vermeinte nur, das EwigMenschliche darzustellen. Die Geschichte galt also fur das Milieu, ftur den Menschen galt sie nicht.

Das Milieu ist so eigentumlich unwichtig, rein als Anlass aufgefasst, es ist eine variable Grosse und etwas eigentumlich Unmenschliches; es existiert eigentlich ohne den Menschen, es tritt ihm als geschlossene Einheit gegentiber, ihm, dem immer Unverănderten, der fixen Grösse. ${ }^{3}$

Als Gegenbeispiel fthrt Brecht die folgende Situation an, und sie sei hier zitiert als klares Beispiel seiner These:

Auf der Bthne sei folgendes darzustellen: Ein junges Madchen verlasst ihre Familie, um eine Stellung in einer grösseren stadt anzunehmen. (Piscators 'Amerikanische Tragoldie'). Ftur das burgerliche Theater ist dies eine Angelegenheit von geringer Tragweite, sichtlich der Beginn einer Geschichte, das, was man erfahren muss, um das Nachfolgende $z u$ verstehen... In gewisser 
Hinsicht ist der Vorgang allgemein: junge Madchen nehmen Stellungen an... Dass die Familie sie gehen lasst, ist nicht Gegenstand der Untersuchung, es ist glaubhaft (die Motive sind glaubhaft). Ftur das historisierende Theater liegt alles anders. Es wirft sich ganz und gar auf das Eigenttuliche, Besondere, der Untersuchung Bedurftige des so alltalglichen Vorgangs. Wie, die Familie entlasst aus ihrer Hut ein Mitglied, damit es sich nunmehr selbständig, ohne Hilfe den Lebensunterhalt verdient? Ist es dazu imstande? Was es hier, als Familienmitglied, gelernt hat, wird ihm das helfen, den Unterhalt zu verdienen? Konnen Familien ihre Kinder nicht mehr behalten? ... Ist das so bei allen Familien? War das immer so? Das sind Fragen (oder ein Teil von ihnen), welche die Schauspieler zu beantworten haben, wenn sie den Vorgang als einen historischen, einmaligen darstellen wollen, wenn sie hier eine sitte aufzeigen wollen, die Aufschluss gibt ther das ganze Gefthge der Gesellschaft einer bestimmten, (vergänglichen) Zeit. Wie soll aber ein solcher Vorgang dargestellt werden, dass sein historischer Charakter hervortritt? Wie kann die Wirrnis unserer ungltaklichen zeit auffullig gemacht werden? Wenn die Mutter unter Ermahnungen und moralischen Forderungen der Tochter den Koffer packt, der sehr klein ist - wie zeigt man das: so viele Forderungen und so wenig wäsche? 4

Wenn Brecht also versuchte, nicht das Ewig-Menschliche,

sondern das Spezifische an seinen Charakteren herauszuarbeiten, so bestand er doch darauf, dass seine Figuren typisch sein mussten. Hierin liegt im Grunde kein widerspruch, wenn man Brechts Erklärung des Typischen annimmt:

Historisch bedeutsam (typisch) sind Menschen, die nicht die durchschnittlich häfigsten oder am meisten in die Augen fallenden sein mögen, die aber ftur die Entwicklungsprozesse der Gesellschaft entscheidend sind. Die Auswahl des Typischen muss nach dem ftur uns Positiven (Wunschbaren) wie nach dem Negativen (Unerwhinschten) hin erfolgen... Die eigentliche Bedeutung des Wortes "typisch," fur die es von Marxisten als wichtig genannt wurde, ist: geschichtlich bedeutsam. Dieser Begriff gestattet, auch scheinbar winzige, seltene, 
thersehene Vorkommnisse, sowie unscheinbare, oft oder selten vorkommende Menschen ans Licht der Dichtung zu ziehen, weil sie geschichtlich bedeutsam, das heisst fur den Fortschritt der Menschheit, das heisst ftrr den Sozialismus wichtig sind. Diese Vorkommnisse und Menschen mtlssen aber dann realistisch, das heisst mit ihren widersprtichen dargestellt werden. 5

Typisch wird also nicht als allgemein-menschlich sondern als kennzeichnend fthr eine gewisse soziale Gruppe und historische Zeit definiert. Das Besondere des typischen 'Helden' entwickelt sich dann im Detail und in den widersprtuchlichen Kraften, denen er ausgesetzt ist und auf die er reagiert.

wahrend das burgerliche Theater also vom individuellen Charakter ausgeht und beim Allgemein-Menschlichen landet, geht das epische Theater Brechts vom Typus zur spezifischhistorischen Analyse. In einer Formel ausgedrtlckt könnte man sagen, das bthrgerliche Theater geht vom Besonderen zum Allgemeinen, wathrend sich Brecht vom Allgemeinen zum Besonderen, oder doch Konkreten, durcharbeitet.

Obwohl Brecht davon tiberzeugt war, dass das Unvorhergesehene, ja Schockierende im Charakter natturlich war und daher realistisch auch so dargestellt werden musste, hatte der "epische" Charakter Brechts noch einen weiteren Zweck: er wird bewusst als ein Teil der Verfremdungstechnik angewendet.

Brechtschtler Wekwerth in seinem Buch Theater der Veränderung definiert dies so:

Verfremden ist also wirkliches Bekanntmachen mit Hilfe der weltverändernden Formel: Einheit - 
Kritik - Einheit,"

oder anders ausgedrthckt: "Verstehen - Nichtverstehen Verstehen." 6

Das anfüngliche Verstehen wäre der traditionelle Charakterbegriff; durch die Verfremdung entsteht zeitweilig eine Periode des Sich - Wunderns, des Mangels an traditionellen orientierungspunkten. In der Neuordnung des Dargestellten endlich, im zweiten Verstehen, findet der Lernprozess des Zuschauers seinen Abschluss.

Wie Kohlhase andeutet geht es Brecht immer "um den Nachweis, dass den Dingen eine ordnung und Harmonie innewohnt, die sich als scheinbare erweist, sobald man sie mit anderen Augen ansieht." 7

In Die Ausnahme und die Regel wird den Zuschauern diese Verfremdungshaltung (Grimm) ausdrthcklich nahegelegt:

Findet es befremdend, wenn auch nicht fremd... Untersucht, ob es notig ist,

Besonders das tbliche!

Wir bitten euch ausdrticklich, findet

Das immerfort

Vorkommende nicht naturlich! ${ }^{8}$

Es ist also ein Teil des dialektischen Systems Brechts, den traditionellen Charakter als "burgerlich-harmonische Einheit" aufzulosen und umzudeuten.

Brecht ging in seiner Insistenz auf Wandel und Widerspruch im Charakter bis zur (sicher beabsichtigten) Ubertreibung. Von sich selbst sagte er: In mir habt ihr einen, auf den konnt ihr nicht bauen. Kohlhase meint, dass es seine besondere Art von sophistication war, "den 
Fehler zur Methode zu erheben und die Kritik daran wieder abzufangen, indem er diese Technik offen zur Schau stellte." 9 Mit "Fehler" meinte Kohlhase hier wohl den Umschlag der Handlung ins Widersprtuchliche, Erstaunen und Arger Erregende, die unerwartete Abunderung des Blickpunkts. Der Wandel wird sogar zur Lebensnotwendigkeit erhoben. In einer seiner Keunergeschichten, Das Wiedersehen, heisst es: "Als Herr Keuner nach langer Zeit von einem Bekannten mit den Worten begrtisst wurde: 'Sie haben sich gar nicht verundert', sagte er erschrocken: 'Oh!' und erbleichte."10

Es ist ein niederschmetterndes Urteil, wenn jemand feststellt, dass man keinerlei Wandel durchgemacht habe. Zum selben Thema heisst es in einer anderen Geschichte, Uber den Verrat: "Der Mensch kann nichts versprechen... Der Denkende verrat. Der Denkende verspricht nichts, als dass er ein Denkender bleibt."ll Treue zu sich selbst heisst also selbstveränderung. Prinzipientreue ist bedeutungslos geworden in einer welt, in der es absolute Prinzipien nicht mehr gibt. Die Tat von morgen hat mit der Uberzeugung von heute kaum etwas zu tun.

In Brechts Schriften zum Theater heisst es ther die Wechselwirkung zwischen Tat und Charakter:

Es ist eine zu grosse Vereinfachung wenn man die Taten auf den Charakter und den Charakter auf die Taten abpasst; die Widersprtiche, welche Taten und Charakter wirklicher Menschen aufweisen, lassen sich so nicht aufzeigen. Die gesellschaftlichen Bewegungsgesetze können nicht an den 'Idealfallen' demonstriert werden, da die 'Unreinheit' (Widersprthchlichkeit) gerade zu Bewegung. und Bewegtem gehort. Es ist nur. 
notig - dies aber unbedingt - dass im Grossen und Ganzen so etwas wie Experimentierbedingungen geschaffen werden, das heisst, dass jeweils ein Gegenexperiment denkbar ist... Die Einheit der Figur wird namlich durch die Art gebildet, in der sich ihre einzelnen Eigenschaften wiedersprechen.12

Hier besteht Brecht also nicht nur auf der Widersprthchlichkeit innerhalb seines Charakters sondern er gibt der Persornlichkeit seines Helden auch eine weitere Dimension, indem er verlangt, dass er noch eine zweite Handlungsweise projiziere ther die tatsăchlich dargestellte hinaus. Unter diesen "Experimentierbedingungen" wird die Persona des Sttucks zum wissenschaftlichen Versuch, einer unter vielen herausgegriffen, wobei die anderen, nicht dargestellten, als Möglichkeiten sozusagen mitgeliefert werden. Werden der Mensch also als fortlaufender Prozess und die Umstande des Sttckes als Faktoren eines Experiments betrachtet, so bleibt der Mensch selber immer unfertig, ein Kompositum aller Möglichkeiten, die ihm die Gesellschaft offen lässt. So erklät Brecht einer Gruppe von Schauspielern:

Viele gehen davon aus, dass der Mensch eine fertige Sache ist, so und so aussehend in diesem Licht, so und so in jenem, dies und das sagend in dieser Lage, dies und das in jener, und so versuchen sie von Anfang an diese Figur zu erfassen und ganz zu werden. Es ist aber besser, den Menschen als eine unfertige Sache zu betrachten und inn langsam entstehen zu lassen, von Aussage zu Aussage und von Handlung zu Handlung.

Indem er ja sagt, indem er nein sagt

Indem er schlagt, indem er geschlagen wird

Indem er sich hier gesellt, indem er sich dort gesellt

So bildet sich der Mensch, indem. er sich ündert 
Und so entsteht sein Bild in uns

Indem er uns gleicht und indem er uns nicht gleicht. (Vergleich 'Bildnis' bei Frisch!)

So sollen wir nicht einen darstellen, fragt ihr, der sich gleichbleibt, indem er in den verschiedenen Situationen verschieden auftritt?

Aber soll es dann nicht ein Bestimmter sein, der sich andert, in einer bestimmten Weise, anders als ein anderer sich undert. Die Antwort ist: es wird ein Bestimmter sein, wenn ihr nur alles der Reihe nach gut ausflihrt und euch auch an Menschen erinnert, die ihr beobachtet habt. Es ist so viel moglich, ein Bestimmter andert sich in einer bestimmten Weise und bleibt der Bestimmte lange Zeit, und eines Tages ist er ein anderer Bestimmter, das kann vorkommen. Ihr sollt nur nicht einem Gesicht nachjagen, einem das alles von Anfang an in sich hat und nur seine Karten ausspielt, je nach Gelegenheit... 13

In seinen Schriften zum Theater, erzahlt Brecht, dass ein sehr "dümonischer" Schauspieler mit seinen Figuren unzufrieden gewesen sei. Der Schauspieler soll bemerkt haben: "Das ist doch keine Figur. Einmal sagt er so, einmal so. Er weiss tberhaupt nicht, was er sagt." Damit meinte der Mann, Brechts Figur sei nicht aus dem Leben gegriffen, während er ftur Brecht nur die Echtheit der Figur damit bestatigte. "Wer sagt nicht einmal so, einmal so?" fragt Brecht. "Wer weiss, was er sagt? Ein ganz mittelmassiger Mensch."14

Brecht fthrt diesen Gedanken weiter, indem er vorschlägt, die Darstellung berthmter Personlichkeiten zu andern.

Niemals durfte man sie lediglich das sagen lassen, was dazu notig scheint, dass die bekannte Handlung, die sie begingen, zustande kommt, sondern man musste, der Wahrheit des wirklichen Lebens folgend, alle ihre Umwege, alle ihre Fehler aufzuhlen und sie so 
darstellen, dass ihre (den Inhalt der

Geschichtsbucher bildenden) Taten um so unbegreiflicher und phunomenaler erscheinen. Es ist, wenn der Dramatiker die Figur etwa des dritten Richard darstellt, nicht seine Aufgabe, uns die Taten dieses Menschen möglichst begreiflich zu machen, sondern sie uns als ganz ungeheuerlich, unmenschlich, fremdartig, ihren Tater als bemerkenswertes, aber fast unzugängliches Tier vorzustellen. Dadurch entsteht der Zuwachs im Zuschauer, denn er erlebt die Reichhaltigkeit und durch sein Verstundnis keineswegs erschopfbare Gottlichkeit der Welt.15

Man konnte sich vorstellen, dass es mit dieser Darstellungsweise Brechts der Biographien berthmter Männer keine Vorbilder ftur die erzieherischen Unterrichtsbticher unserer schulen mehr gabe.

Wenn Brecht fortfuhrt, die dialektische Dramatik arbeite "Ohne Psychologie und ohne Individuum,"16 so meint er damit, dass die Psychologie meist dazu gebraucht wird, das Verhalten des Menschen im Rückblick auf seine Vergangenheit hin zu erklären, und es dadurch selbstverstandlich $\mathrm{zu}$ machen. Indem das Handeln aber nicht als selbstverstundlich sondern als aufullig hingestellt wird, soll das Augenmerk des Zuschauers auf die Zusammenhänge der Handlungen, auf die Prozesse innerhalb bestimmter Gruppen hingelenkt werden, wie sie sich in der Gegenwart vollziehen. Brecht illustriert in immer neuen Variationen den Zusammenhang zwischen seiner Charakterdarstellung und dem Lehrziel seiner Dramen. In den Schriften zum Theater formuliert er aufs Neue die Forderungen der nichtaristotelischen Dramatik an den Zuschauer. Er muss imstande sein, in einer ganz bestimmten erlernbaren Haltung die 
Vorgănge auf der Bthne zu verfolgen, sie in ihrem allseitigen Zusammenhang und totalen Verlauf zu begreifen. Und zwar zum Zwecke einer grthdlichen Revision seines eigenen Verhaltens. Er darf sich nicht spontan mit bestimmten Figuren identifizieren, um dann lediglich an ihrem Erleben teilzunehmen. Er geht also nicht aus von ihrem intuitiv erfassten "Wesen," sondern aus ihren Ausserungen und Handlungen setzt er die Gesamtprozesse zusammen. ${ }^{17}$ Es ist mittels dieser "Zusammensetzarbeit" des Zuschauers, die durch Brechts episodenhafte Charakterdarstellung zustande kommt, dass sich Brechts Charakterkonstruktion sowohl auf seine erfundene Figur als auch auf seinen leibhaftigen Zuschauer auswirkt. 
KAPITEL VII

\section{DER CHARAKTER DES GEGENSPIELERS}

Während Brecht immer bemtht war, an seinen Helden jede Facette der Figur herauszuarbeiten und so weit wie möglich die positiven und Schattenseiten gleicherweise darzustellen, hat er seine Gegenspieler oft summarisch abgetan. Hüufig wurden sie vereinfacht und zum Symbol reduziert, indem sie mit Masken (spitzen Huten, weissgefürbten Gesichtern) auftraten. Ihre Sprache erschopfte sich oft in Klischees, ihre Gesten hatten marionettenhaft zu sein. Sie verfielen der Groteske. Da sie Vertreter der besitzenden Klassen waren, des Establishments und somit des "Bösen," wurden ihre individuellen Zthge geopfert, um das dialektisch-politische Argument um so klarer aufzuzeigen.

Jendreieck sieht den Gebrauch von Masken bei den Gegenspielern als Mittel zur "Interpretation des gesellschaftlichen Seins." Er zitiert Brecht, der von Deformierungen der Physiognomien bei Parasiten und von Verwthstungen der Gesichter bei den Herrschenden spricht. Brecht sah da eine "Lahmung der Muskulatur." Masken, so meinte Jendreieck, seien also nicht als Symbol zu betrachten, sondern als eine Uberhohung der Realitat um die Stellungnahme des Theaters zu unterstreichen. ${ }^{1}$ Taeni sieht die "Uberstilisierung 
jener Charaktere, die die Gesellschaft bilden" als Verfremdungsmittel. 2 In den Rundkopfen, meint er allerdings, sei Brecht zu weit gegangen.

Ihre Charakterisierung, insbesondere der Nazis, erschbpft sich im allgemeinen in flachster $\mathrm{Ab}-$ straktion: Allzu offensichtlich handelt es sich hier um Typen, deren phrasenhaftes Gerede nur dazu dient, bestimmte, vom Autor fthr kritikwlirdig befundene Geisteshaltungen auszudrucken. Als blosse Karikaturen sind sie aber naturlich weder wahrhaft komisch, noch vermogen sie der brutalen geschichtlichen Wirklichkeit des einstigen Nazideutschland genthge zu tun. 3

Wie auch Giese andeutet verwendet Brecht oft das Mittel der Karikatur ftur die Zeichnung des Gegenspielers. 4 Herr Puntila zum Beispiel bezeichnet den jungen Attaché, seinen Schwiegersohn in spe, als "befrackte Heuschrecke." Mit diesem Bild ist der junge Mann schon abgestempelt und erledigt. Der Knecht Matti hingegen ist fur Puntila "ein Mensch"; der Mann des Volkes also hat wieder ein Recht auf Humanitat. Dem Helden, dem Mann des volkes gilt Brechts Aufmerksamkeit und auf ihn verwendet er seine handwerkliche Fertigkeit.

Im Kleinen Organon stellt Brecht fest, dass das traditionelle Theater gerade umgekehrt verfuhrt. Er meint, die "Ungenauigkeit" der Theaterleute sei dadurch zu entschuldigen, dass sie Theater ja als ware produzierten, als Konsumartikel. Hier heisst es ferner:

Wir sehen ihre Fahigkeit, Menschen abzubilden, allenthalben am Werk; besonders die Schurken und die kleineren Figuren zeigen Spuren ihrer Menschenkenntnis und unterscheiden sich voneinander, aber die Mittelpunktsfiguren mussen allgemein gehalten werden, damit der Zuschauer sich mit 
ihnen leichter identifizieren kann, und jedenfalls mussen alle Zthge aus dem engen Bereich genommen sein, innerhalb dessen jedermann sogleich sagen kann: ja, so ist es... Alles, worauf es den Zuschauern in diesen Hausern ankommt, ist, dass sie eine widerspruchsvolle Welt mit einer harmonischen vertauschen konnen, eine nicht besonders gekannte mit einer träumbaren. 5

Im traditionellen Theater war der Held also oft nach der Schablone geschaffen und nur die Bösewichter zeigten widersprthchliche und daher realistische zthge. Nur in ihnen wagte der Autor seine Menschenkenntnis zu zeigen. Der Held war sibi constans, der Bösewicht war unzurechenbar. Brecht wollte aber gerade im Helden die möglichen Alternativen zu einer gegebenen Handlung aufzeigen, und es war der Gegenspieler, der der schablone verfiel. 


\section{DER GESPALTENE MENSCH}

Diese Untersuchung will sich in erster Linie mit solchen Figuren beschaftigen, die sorgsam durch "zahllose Aufbauakte" ${ }^{1}$ zuerst vom Autor, aber dann auch von den Schauspielern "zusammengestellt" wurden. Es ist gerade in diesen Figuren wie etwa Galilei, dass der Begriff des "epischen Charakters" im Vergleich zum traditionellen Helden am besten zum Ausdruck kommt.

Jedoch Brecht had auch noch andere Wege gefunden, dem Zuschauer die Gewohnheit zu nehmen, einen dramatischen Charakter "aus einem Guss" zu erwarten, mit anderen Worten, den Charakterbegriff zu verfremden.

Zuerst sei hier die Doppelrolle erwahnt, die bei Der Gute Mensch von Sezuan zur Hosenrolle wird. Ursprthnglich eine Prostituierte trifft Shen-Te die wahre Liebe und kann sich deshalb nicht mehr durch Prostitution finanziell sanieren (sie könnte den ungeliebten aber reichen Frisor heiraten. Die Ehe ist bei Brecht oft eine Form der Prostitution.) Um ihr personliches Gllick zu retten, muss sie eine zweite Rolle auf sich nehmen, nămlich die des harten Businessmans Shui-Ta; sie wird also durch die Gesellschaft dazu gezwungen, sich zu spalten. Obwohl sie 
am Anfang ihre beiden Rollen kontrollieren kann, verliert sie-wie Goethes Zauberlehrling - nach und nach die Gewalt thber ihre Schopfung. Es ist das schlechte, neue Ich, das die Gesellschaft respektiert. Der ursprungliche "Charakter," das alte Ich, ist nicht lebensfuhig. Giese kommentiert hiezu:

Die Doppelrolle ist der sinnlich-konkrete Beweis, die je erneut vorgespielte Nummer, dass es unter kapitalistischen Verhaltnissen gerade die Tugenden sind, die dem einzelnen gefuhrlich werden.... Die Doppelrolle ist bei Brecht immer Ausdruck der Existenzspaltung des Menschen in kapitalistischer Gesellschaft.2

Viele Figuren Brechts leben auf zwei Ebenen in einer Art schizophrener spaltung. Herr Puntila kann ganz nach Belieben und wie es ihm eben gthstig erscheint mittels Alkohol und Dampfbad von einer Rolle zur anderen wechseln. Mayer sieht auch noch eine dritte schicht hier, nämlich den Knecht Matti "als Wahrheit des Herrn." 3

In den Sieben Todstunden befindet sich Anna in einem thnlichen Dilemma wie Shen-Te/Shui-Ta. Als Anna I und Anna II fuhrt sie einen "Dialog mit einer stimme" indem sie, zwischen den zwei Anna Rollen wechselnd, einmal die unpraktischen Tugenden, ein andermal eine auf praktischen Vorteil gerichtete Lebensweise verteidigt.

Weniger drastisch-aber doch auch gespalten-sind Figuren wie der grausame Kapitalist Mauler in der Die Heilige Johanna, der sich in biblischen Sprthchen ergeht, die Prostituierte in Mahagonny, die sich als kleine Geschäftsfrau gibt, Peachum der Burger in der Dreigroschenoper, 
der als Verbrecher lebt, und Mcheath, "Mackie Messer," der ganz burgerliche Ansichten und Gewohnheiten hat.

Brecht selber kommentiert zum Polizeipräsidenten

Brown aus der Dreigroschenoper

Der Polizeipralsident Brown ist eine sehr moderne Erscheinung. Er birgt in sich zwei Personlichkeiten: als Privatmann ist er ganz anders als als Beamter. Und dies ist nicht ein Zwiespalt, trotz dem er lebt, sondern einer, durch den er lebt. Und mit ihm lebt die ganze Gesellschaft durch diesen seinen Zwiespalt.4

Brecht sieht also hier die Spaltung als eine zwischen privatem und offentlichem Leben, zwischen pater familias und Beamtem. Man könnte diesen Unterschied tubrigens auch bei Shen-Te/Shui-Ta und Herrn Puntila feststellen sowie bei vielen anderen Figuren Brechts. Fur den Geschaftsmann ist dieser Zwiespalt vorteilhaft während er den Frauenfiguren, die ihr Leben auf Gefthle aufbauen wollen, zum Verhăngnis wird.

Einer anderen Form der Zweiteilung unterwirft sich der Kellner im Dickicht der städte. Er schafft sich eine Traumwelt, die er als ein besserer und glthcklicherer Mensch nach der Arbeit bewohnt. Sein erniedrigender Beruf hat ihn sich selbst so entfremdet, dass er sich nur in einer Phantasieversion annehmen kann, eine andere und psychologisch gefahrliche Form der Spaltung. Giese meint hiezu:

Insofern es (das Individuum) die Ursache dieser spaltung nicht erkennt, sondern unbeirrt an der Moglichkeit festhalt, im Privaten seine Identitat wiederzuerlangen, ohne doch an den Mitmenschen sich "entäussern" zu können, entsteht ein automatisch ablaufender Prozess, der in Katzenjammer oder ungenaue Utopie munden muss. 5 
Ein weiteres Mittel, das Brecht benutzte, um seine Charaktere $z u$ verfremden, ist der Prozess der "Ausloschung" oder "gesellschaftlichen Umfunktionierung." 6

Schon bei Galy Gay in Mann ist Mann findet sich ein symbolischer Tod mit Wiederauferstehung in gesellschaftlich nthtzlicherer Form. In den politischen Tendenzstucken wird dieser Prozess mehrmals wiederholt. Er besteht aus einer rituellen Selbstausleerung, aus einer Aufgabe aller Individualitat und sogar des Namens. In der Betonung der freiwilligen Unterordnung und des absoluten Gehorsams liegt etwas Religioses. Wie in einer Priesterweihe wird das weltliche Ich, der alte Charakter, abgelegt, ausgeleert und der neu Geweihte aufersteht, erftilt mit den Idealen und Forderungen der revolutionaren Gruppe, der er sich angegliedert hat. Die Spaltung ist also hier eine zasur, die das Leben in ein Vorher und Nachher teilt. (Brechts politische stucke entstanden grosstenteils in der Depressionszeit, in einer Periode, wo er selbst mit dem Kommunismus beschaftigt war, als die Arbeitslosigkeit ihre Hohe erreicht hatte und Hitler seinen politischen Aufstieg begann. Es schien Brecht damals, dass nur extreme Mittel diesen extremen Zuständen gewachsen waren.)

Brecht hat also auch hier wieder mit immer neuen Schemata und Kunstgriffen gezeigt, dass der Mensch sibi non constans ist, dass es einen Charakter im traditionellen Sinn nicht gibt, ja in unserer Gesellschaft nicht geben kann. 
KAPITEL IX

DIE DARSTELLUNG DES EPISCHEN CHARAKTERS AUF DER BUFNE

\section{Quellen der Inspiration}

Um den neuen epischen Charakter auch auf der Bthne entsprechend zur Geltung zu bringen verlangte Brecht vor allem Realismus in der Darstellung. Er sah einerseits die Mode der Stanislawski-Methode, die vom Schauspieler verlangte, dass er sich der Illusion hingab, die dargestellte Figur selbst zu sein. Anderseits spielten die Darsteller nach einer leeren Routine, die klassịsch zu sein vorgab.

In seinen "Augsburger Theaterkritiken" ruft er aus:

Ich protestiere dagegen, dass Schiller unserer Jugend so tbermittelt wird... vollig unmöglich (völlig unmolglich) (sic) Geffers Karl. Ich habe den besten Willen, diesem unglthcklichen Mann Recht widerfahren zu lassen. Aber das geht nicht. Leere, dumme Deklamation! Der Bonvivant als Räuberhauptmann! Steht da und macht den Mund auf, dass man meint, es whrden Eier herauskullern.... I

Um der Wirklichkeit nahe zu bleiben, schulte Brecht sich an Beispielen, die genaue Beobachtung der Vorgănge und logische Schlussfolgerungen betonten. Brecht fand diese Vorbedingungen im Boxkampf, im Kriminalroman und in der Beschreibung eines strassenunfalls. In allen diesen Fallen kommt es nicht auf Gefthle und Ideale, sondern auf harte, zu beobachtende Tatsachen an. 
Beim guten englischen Kriminalroman findet Brecht nicht nur fairness sondern auch "moralische stärke," da der Leser nicht getäuscht wird. Alles Material wird ihm unterbreitet. Er wird instand gesetzt, die Lobsung selbst in Angriff zu nehmen.

Es ist erstaunlich, wie sehr das Grundschema des guten Kriminalromans an die Arbeitsweise unserer Physiker erinnert. Zuerst werden gewisse Fakten notiert.... Dann werden Arbeitshypothesen aufgestellt, welche die Fakten decken konnen. Durch den Hinzutritt neuer Fakten oder die Entwertung bereits notierter Fakten entsteht der Zwang, eine neue Arbeitshypothese zu suchen. Am Ende kommt der Test der Arbeitshypothese: das Experiment. Wenn die These richtig ist, dann muss der Mürder auf Grund einer bestimmten Massnahme dann und dann da und da erscheinen. Entscheidend ist, dass nicht die Handlungen aus den Charakteren, sondern die Charaktere aus den Handlungen entwickelt werden. Man sieht die Leute agieren, in Bruchstticken. Ihre Motive sind im dunkeln und mussen logisch erschlossen werden. Als ausschlaggebend fur ihre Handlungen werden ihre Interessen angenommen, und zwar beinahe ausschliesslich ihre materiellen Interressen. Nach ihnen wird gesucht.

Man sieht die Annäherung an den wissenschaftlichen Standpunkt und den enormen Abstand zum introspektiv psychologischen Roman.

Der Kriminalroman handelt vom logischen Denken und verlangt vom Leser logisches Denken... es ist eine intellektuelle Gewohnheit.2

Brecht weist darauf hin, dass der Kriminalromanschreiber "die Kunst der Verfuhrung" beherrschen muss. Zuerst provoziert er unsere Vorurteile und wir vergessen immer wieder, dass nur Motiv und Gelegenheit entscheiden, und nicht die sympathischen oder unattraktiven Zuge der Personen. "Der menschenfreundliche Botanist ist nicht der Mörder," lässt er uns ausrufen. "Einem zweimal vorbestraften Gärtner ist alles zuzutrauen," lässt er uns seufzen. 
Er fthrt uns irre durch seine Charakterschilderungen. Wir durfen nie vergessen, dass es lediglich die gesellschaftlichen Umstände sind, die das Verbrechen ermöglichen oder notig machen, denn "sie vergewaltigen den Charakter, sowie sie ihn gebildet haben." 3

Im Kriminalroman geschieht der Aufbau der Figuren im allgemeinen zugweise; es besteht eine stündige Verkntpfung mit den Handlungsweisen. "Am Aufbau des Charakters nimmt der Leser als an einer Tutigkeit teil; es ist eine Enthtlllung, die gemacht sein will..." Brecht nennt dieses Verfahren eine "Gipfelleistung der literarischen Psychologie." Sie ergibt sich daraus, meint er, dass hier das bturgerliche Leben als Erwerbsleben aufgefasst und beschrieben wird. 4

Brecht bewundert also im Kriminalroman besonders den Aufbau der Situation und dadurch des Taters durch sichtbare und greifbare Indizienbeweise, durch Clues, die das Resultat einer kriminellen Tutigkeit sind. Der Charakter sagt thber sich selber nichts aus, ja er hat allen Grund, seine wahren Motive $\mathrm{zu}$ verheimlichen. Jedoch der Schriftsteller liefert dem Leser genug Beweismaterial, damit er sich ein Urteil bilden kann. Genau das ist auch Brechts Absicht in seinen Personendarstellungen.

Ein ahnliches Beispiel wie der Kriminalroman stellt die berthmte "Strassendemonstration" dar, die Brecht ein "Grundmodell ftur episches Theater" nennt. 5 Der Augenzeuge eines Verkehrsunfalls demonstriert einer Menschenansammlung, wie das Ungluck passierte. Die Hauptsache dabei ist, "dass 
der Demonstrierende das Verhalten des Fahrers oder des Uberfahrenen oder beider in einer solchen Weise vormacht, dass die Umstehenden sich tber den Unfall ein Urteil bilden können." Obwohl der Demonstrant genau imitiert, was er gesehen hat, wiederholt er doch nicht alles und wird in der Auswahl seiner Gesten beeinflusst von den kthftigen Konsequenzen, die auf den Unfall folgen konnten. Hat der Chauffeur seine Entlassung zu befturchten, der tberfahrene hohe Klinikkosten? Die Demonstration konnte beherrscht sein von der Frage des Schadenersatzes. "Das ist das Feld, auf dem der Demonstrant seine Charaktere aufbaut," bestimmt Brecht. ${ }^{6}$ Ein weiteres wesentliches Element der Strassenszere ist, dass der Demonstrant seine Charaktere ganz aus ihren Handlungen ableitet. ${ }^{7}$ Er imitiert ihre Handlungen und gestattet dadurch Schltisse auf sie. Brecht leitet seine Theorie ftur das epische Theater in folgender Weise von der Strassendemonstration ab:

Ein Theater, das ihm (dem Demonstranten) hierin folgt (im Ableiten der Charaktere aus ihren Handlungen), bricht weitgehend mit der Gewohnheit des thlichen Theaters, aus den Charakteren die Handlungen zu begrtinden, die Handlungen dadurch der Kritik zu entziehen, dass sie als aus den Charakteren die sie vollziehen, unhinderbar, mit Naturgesetzlichkeit hervorgehend dargestellt werden. Fttr unseren Strassendemonstranten bleibt der Charakter des zu Demonstrierenden eine Grbsse, die er nicht vollig auszubestimmen hat. Innerhalb gewisser Grenzen kann er so und so sein, das macht nichts aus. Den Demonstranten interessieren seine unfallerzeugenden und unfallverhindernden Eigenschaften...

Dieses "Grundmodell des epischen Theaters" erlaubt Brecht noch ein weiteres Element seines Theaters vorzufthren, 
nămlich die Doppelrolle des Schauspielers, hier des Demonstranten. Der Strassendemonstrant, sagt Brecht

trägt ständig zwei Situationen Rechnung. Er benimmt sich naturlich als Demonstrant und er lässt den Demonstrierten sich nathrlich benehmen. Er vergisst nie und gestattet nie zu vergessen, dass er nicht der Demonstrierte, sondern der Demonstrant ist. Das heisst: was das Publikum sieht, ist nicht eine Fusion zwischen Demonstrant und Demonstriertem, nicht ein selbstandiges, widerspruchsloses Drittes mit aufgelosten Konturen... Die Meinungen und Gefthle von Demonstrant und Demonstriertem sind nicht gleichgeschaltet. 8

Der Schauspieler darf also nie bestrebt sein, seine Rolle zu "verkorpern," sondern er bleibt immer Erzühler, Demonstrant. Brecht geht also hier noch weiter in dem er nicht nur die Einheit des Charakters zerstort, sondern auch noch die Identitat von Schauspieler und dargestellter dramatis personae. Der Schauspieler wird zum Lehrer und die dargestellte Figur zum Lehrmaterial.

Brecht sah sich nach anderen Vorbildern um, die ihm helfen sollten, den Charakter seiner Figuren in Handlungen aufzulysen. Charlie Chaplin und der Clown Valentin waren ein entscheidender Einfluss; der Stummfilm zeigte ihm die Möglichkeit, ganz ohne Worte auszukommen und das Hörspiel stellte das Problem, Handlungen ohne bildliche Darstellung zu zeigen. Die Mechanik seines Mercedes, die Strategie eines Fussballspiels, die Berechnungen, die sein Freund der Architekt Max Frisch auf dem Bau anstellte waren logische Systeme, die er $\mathrm{zu}$ verwenden versuchte. Die Plastiken von Barlach scheinen wie Brechtfiguren, mitten in ihrer Tatigkeit in einen Dornroschenschlaf versetzt. 
Brecht beschreibt:

Da ist der Buchleser, die Bronze von 1936. Ein sitzender Mann, vorgebeugt, in schweren Händen ein Buch haltend. Er liest neugierig, zuversichtlich, kritisch. Er sucht deutlich Iolsungen dringender Probleme im Buch... Der Buchleser gefullt mir besser als Rodins berthmter Denker, der nur die Schwierigkeit des Denkens zeigt. Barlachs Plastik ist realistischer, konkreter, unsymbolisch.9

$\mathrm{Da}$ ist die Bettlerin mit Schale, in Bronze, von 1906. Eine mächtige Person mit hartem Selbstbewusstsein, von der kein Dank fur milde Gaben zu erwarten ist...

...Von dieser Plastik, entstanden im verhangnisvollen Jahr 1933 (Sitzende Alte) steigen wieder Erinnerungen und Vergleiche auf. Ein Jahr vorher stellte in Berlin die Weigel die Wlassowa auf der Bthne dar. Statt der Passivitat die Aktivitat, statt des Opfers der Unmenschlichkeit die Menschlichkeit. Ich kann mir einen Arbeiter vorstellen, der die Alte Barlachs mit dem Ellbogen anstbsst: Herrsche! Du has alles, was dazu gehbrt.10

In diesen Plastiken sieht Brecht Aktivitat und Produktivităt, die in der Haltung der jeweiligen Figur ausgedrthkt sind. Der Gesichtsausdruck, der wie in der Laokoongruppe den ganzen seelischen Gehalt der Figur ausstrahlt, ist ftur Brecht nicht wichtig und bei Barlach auch oft kaum herausgearbeitet.

\section{Die epische Spielweise}

Wolfgang Roth, der zwischen 1928 und 1933 als Buhnenbildner an mehreren Produktionen Brechts mitarbeitete und heute an der Universitat von New York lehrt, sagt folgendes tuber Brecht:

Brecht's genius and craftsmanship, his tremendous involvement, made it possible and necessary that he often contradicted himself. He was an 
intuitive man whose work came first, his theories later. There is no Brechtian method; the attempt by people less talented than Brecht to create a Brechtian theater by applying Brechtian theory can only lead to failure... He himself often debunked the epic label... He smiled when confronted with questions or doubt: "I don't know myself what I want, let's try something else."Il

Roth warnt vor Brecht-Imitation, denn Imitatoren verfahren nach einer Schablone auf Kosten des Elements der Uberraschung. Man denkt an das bon-mot "Genêt sans génie." Rttlicke geht nicht so weit, eine Brechtische Methode ganz und gar zu bestreiten, aber auch sie gibt zu:

Von allen Ausserungen Brechts haben diejenigen ther die Spielweise die meisten Missverständnisse hervorgerufen; sie brauchen allerdings mehr als jede andere theatralische Kunst die praktische Demonstration und sind aus der Beschreibung allein kaum zu erfassen. 12

Es dreht sich bei der epischen Spielweise um eine Vorfthrung von gegenseitigen Verhälnissen: der Stückeschreiber zeigt seinen Standpunkt der Gesellschaft gegentber und der Schauspieler fthrt sein Verhaltnis zur Rolle vor, beziehungsweise zum Verhalten seiner Figur. Rtulicke meint, dass die epische Spielweise eine Bereicherung der Theaterveranstaltung darstellt: Der Zuschauer bekommt zu den Gefthlen und Meinungen der Figur noch die des Schauspielers ther die Figur mitgeliefert und ihm werden eigene Meinungen und Gefthle ermoglicht, die sich weder mit denen der Figur noch denen des Schauspielers zu decken brauchen. Die epische Spielweise, die versuchte, auf mehreren Ebenen die Personlichkeit und gesellschaftliche Bedeutung 
einer Figur darzustellen, lief aber durch ihre "unterkthlte" Prasentation Gefahr, formalistisch, leer, ausserlich und mechanisch $\mathrm{zu}$ werden, wie Brecht selbst warnte. Es ist die Aufgabe des Schauspielers, "lebendige, runde, widerspruchsvolle Menschen mit allen ihren Leidenschaften, unmittelbaren Ausserungen und Handlungen" darzustellen. "Die Bthne ist kein Herbarium oder zoologisches Museum mit ausgestopften Tieren." 13

Roth und Rtlicke stimmen also darin tberein, dass die epische Spielweise ausserordentlich tentativ ist; sie entspricht auch ganz dem epischen Charakter, der sich nicht festlegen lasst und von Mal zu Mal verschieden auf der Bthne ausgearbeitet werden kann, je nach der qualitut der Schauspieler, dem Lokal und den politisch-wirtschaftlichen Ereignissen des Tages.

"Meine Regeln," sagte Brecht,

sind nur anzuwenden von Personen, die sich freies Urteil, Widerspruchsgeist und soziale Phantasie erhalten sowie in Kontakt zu den fortschrittlichen Teilen des Publikums stehen, also selber fortschrittliche, vollsinnige, denkende Menschen sind. 14

"Ich kann nun dem Ochsen, der da drischet, nicht das Maul verbinden," fuhrt er fort. "So gibt es eine Reihe von Fehlern bei meinen Schauspielern, die keine Verstosse gegen meine Regeln bedeuten, weil ein Teil ihres Verhaltens von mir nicht geregelt wird." Er erzthlt dann einen Vorfall, in dem sich seine Frau Helene Weigel nicht an die "unterkthlte" Spielweise hielt: 
Selbst die Weigel brach an bestimmten Abenden bei gewissen Stellen in Tränen aus, ganz gegen ihren Willen und nicht zum Vorteile der Darstellung. In einem Stulck, wo sie eine spanische Buluerin im Bthrgerkrieg spielte, hatte sie ihren Sohn zu verfluchen und ihm den Tod zu whinschen, weil sie glaubte, er habe gegen die Generale zu den Waffen gegriffen - in Wirklichkeit war er schon von den Truppen der Generdle erschossen, und zwar beim friedlichen Fischen. Der Bthrgerkrieg dauerte noch an wahrend dieser vorstellung. War es nun, weil der Krieg fur die Unterdrlickten eine schlimme Wendung nahm an dem betreffenden Tag oder weil die Weigel aus irgendeinem andern Grund besonders empfindlich gestimmt war, jedenfalls kamen ihr die Tränen beim Sprechen dieser Verdammung des schon Ermordeten. Sie weinte nicht als Băuerin sondern als Darstellerin uber die Bäuerin. Ich sehe da einen Fehler, aber ich sehe keine meiner Regeln verletzt.

Im Messingkauf rät Brecht den Schauspielern die kritische Haltung an, sogar der von ihm angelegten Rolle gegentber.

Unsere kritische Haltung kommt davon, dass wir nunmehr ein grosses vertrauen in die menschliche Arbeits - und Erfindungskraft gewonnen haben und ein Misstrauen dagegen, dass alles bleiben muss wie es ist.... So wie ein grosszthgiger Ingenieur, der mehr Erfahrungen hat, die Zeichnungen seines Vorgängers korrigiert, neue Linien uber die alten legt, Zahlen durchstreicht und durch andere ersetzt, kritische Bemerkungen und Kommentare einschreibt, konnt auch ihr bei der Zeichnung eurer Figuren verfahren. 15

Aufbau der Figur auf der Bthne: die induktive Arbeitsmethode

Die Art, wie der Schauspieler seine Rolle aus dem widersprthchlichen Material aufbaut, ist im wesentlichen induktiv, meint Rulicke. ${ }^{16}$ Es ist nicht die Gesamtvorstellung der Rolle die ihn leitet. sondern er sammelt die einzelnen Haltungen. Sie zitiert Brecht, der es ganz fth zweckmässig hielt, dass der Schauspieler ganz im 
Praktizieren das sttick und seine Figuren kennenlernte und alles beim Ausfuhren erfuhr.

Alles wird dann gefunden beim Gestalten und das Gestalten bekommt etwas suchendes. Jeder Vorgang muss in sich stimmen und die Figuren als Ganze werden erst allmăhlich mit dem Fortschreiten des Erzahlens genauer. Die Sprunge der Entwicklung werden so weniger leicht vertuscht, die Umwege sind nicht abgeschitten, die Widersprtiche nicht gelost, das heisst geglattet. 17

Brecht selbst hat diese Ideen immer wieder neu formuliert. Die Figur, und damit ihre Charakteranlage, ist nur vorskizziert und muss vom Schauspieler jedes Mal neu erarbeitet werden. Die Betonung dabei liegt immer auf dem Sprunghaften, Widersprthchlichen, Uberraschenden.

Bei dem studium der darzustellenden Figur ist es am besten, schrittweise vorzugehen. Nach solchen Gesichtspunkten oder ftur wen oder fur welche Zwecke soll aber die Figur studiert und aufgebaut werden?

Wahrend der Schauspieler studierend versucht, alle Ausserungen der Figur mit einem Mindestmass seelischer Beteiligung ganz probeweise in die ihm allerbequemsten Tonfalle zu bringen, indem er das Hauptgewicht auf das Finden drastischer Gesten legt, sucht er, bereit zur Uberraschung, aus einzelnen kleinen zthgen das Typische und zugleich Besondere der Figur zu entdecken... Es ist ihm aber nicht erlaubt, etwa zum Zweck der bequemern Vereinigung, einzelne deutlich wahrnehmbare zthge wegzulassen, also im Grund von einer ihm zentral scheinenden Vorstellung vom Ganzen auszugehen. Gerade die nicht passenden, nümich andern widersprechenden Zthge muss er doch zum Bau seiner Figur verwenden... I8

Brecht erlaubt dem Schauspieler also keine "zentral scheinende Vorstellung vom Ganzen." Die zthge, die der Schauspieler ausarbeitet, sind vom "Standpunkt der Aussenwelt her, von den Umlebenden aus, vom Standpunkt der Gesellschaft" her auszuwăhlen. Der andere widersprechende Aspekt 
der Figur ist

die jeweilig andere MOglichkeit des Handelns, die auch aus der Klassenlage und den Verhaltnissen abgeleitet wird...die aber beim Individuum nicht zur Ausfthrung kommt: Sie muss vom Schauspieler sichtbar gemacht werden. Die 'zthge' sind also gewissermassen Schachzthe der Figuren, nicht blosse Ausdrticke einer Person von absoluter unabhängiger Bestimmung... Die Zutge haben gesellschaftliche Ursachen und gesellschaftliche Folgen... Nur aus solchen zthgen aufgebaut werden die Figuren so sein, dass ihre Behandlung moglich ist und auch, von der Figur aus subjektiv gewendet, eine Behandlung der Umwelt durch sie gezeigt werden kann.19

Bei dieser Arbeitsmethode ist es die Aufgabe de:s Probenleiters vor allem, seine Schauspieler davon abzuhalten, in die Routine zurthckzuverfallen.

Unter Probieren versteht er (der Probenleiter) nicht das Einpeitschen von von vornherein in seinem Kopf Feststehendem. Er versteht darunter ein Ausprobieren. Er hat darauf zu dringen, dass jeweils mehrere Moglichkeiten ins Auge gefasst werden. Es ist gefuhrlich flur ihn, sich dazu hetzen zu lassen, dass er möglichst schnell die "einzig richtige" Lösung angibt. Die einzig richtige Losung kann nur eine von immerhin moglichel Losungen sein, wenn es sie therhaupt gibt, und es lohnt sich, andere Lbsungen ebenfalls auszuprobieren, schon weil dadurch die Endlosung angereichert wird. Sie zieht kraft von dem Ausscheidungsakt. Ausserdem ist die Produktivitat der einzelnen Mitwirkenden ungleichmäsigi, sie produzieren in verschiedenem Tempo und benbtigen verschiedene Anreize.... Fur gewbhnlich wird der Probeleiter Mthe haben, ein zu schnelles Aufbauen der Situationen und der Rollen zu verhindern, da gerade dies den Routinierten oder stärkeren (Berthmteren) Gelegenheit gibt, die Produktivitat der andern zu lahmen und selbst konventionelle Iossungen fthr die andern durchzusetzen.20

Brecht besteht weiter darauf, dass die Gesamtlinie nicht durch ein nietenloses Ineinanderschweissen der Details, sondern als eine logische Kette von Details, die noch Detailcharakter haben, entstehen solle. Weiter mussen 
alle andern Möglichkeiten auch ausgefthrt, und nicht nur am Lesetisch diskutiert werden. "Das Uberraschende setzt ein Erwartetes voraus...und das Element der Uberraschung ist ein Grundelement der Wirkung." 21

In diesen letzten Aussprthchen verschmelzt Brecht drei Grundprinzipien seines ktunstlerischen Handwerks: das Zeigen des epischen Charakters, den Aufbau dieses Charakters durch gewissenhafte Kleinarbeit und die Herausarbeitung von stilistischen und Theatereffekten als Beiprodukt des epischen Charakters. Man hat Brecht allerdings dessen angeklagt, die therraschenden Schachzthe seiner Figuren wegen ihres Theatereffekts eingebaut zu haben; diese Arbeit versucht zu zeigen, dass sie eine notwendige Konsequenz seines Charakterbegriffs waren.

In noch anderer Weise haben sich Brechts Ratschläge fthr die Schauspieler von denen Stanislawskis unterschieden. Whhrend die traditionelle Methode verlangte, dass der Schauspieler sich mit seiner Rolle identifizierte, sagte Brecht folgendes:

Ihr werdet wohl immer wieder euch in die Person, die ihr darstellen sollt, in ihre Lagen, in ihre Körperlichkeit, in ihre Denkweise im Geist hineinversetzen mussen. Das ist eine der Operationen des Aufbaus der Figur. Es fordert durchaus unsere Zwecke, nur ist es notig, dass ihr es versteht, euch dann wieder hinauszuversetzen. Es ist ein grosser Unterschied, ob jemand eine vorstellung von etwas hat, wozu er Phantasie braucht, oder eine Illusion, wozu er Unverstand braucht. Wir brauchen ftur unsere Zwecke Phantasie; auch dem Zuschauer wollen wir eine Vorstellung von einer Begebenheit vermitteln, nicht eine Illusion. 22

An anderer Stelle drtuckt er sich noch emphatischer aus. Es 
geht darum, Beobachtungen zu sammeln im Sinne des Behaviorismus:

Krieche in deinen Mann hinein und mache dirs bequem drinnen. Versuche $o b$ du seine Haut sptren kannst und wie sie sich benimmt gegen die Unterschiede der Luft. Probiere sein Darmsystem und sieh nach, was sein Herz aushallt. Auch musst du ihn anstrengen und dann auf das Herz aufpassen. Lass seine Stimme trompeten und vergiss nicht den Flusterton! Iss mit ihm, klatsche seinen kleinen Gedanken Beifall, schaue aus seinen Augen heraus! Wenn er Bier trinken soll in deinem stuck, musst du wissen, wie er Eier isst und Zeitung liest, wie er bei seiner Frau schlaft und wie er in die Grube fahrt. Du musst ihm gewogen sein wie er selbst, und deine Ansichten ther seine Ansichten sind erst in zweiter Linie wichtig. Jedenfalls gehbren sie nicht in die Charakteristik!23

Der Charakter wird also aufgebaut aus genauer Beobachtung der korperlichen Erscheinungen der Figur und wird in keiner Weise in einen ideellen tberbau eingeftugt. Der Charakter scheint wieder als Prozess, hier sogar mit Betonung auf die Kreislaufsysteme.

Rtlicke sieht in dieser Methode eine willkommene Rtuckkehr zur Wirklichkeit:

Brechts Forderung, dass der Schauspieler, der die Totalitat des Gesellschaftlichen und Individuellen sichtbar machen soll, nicht ganz und gar in seiner Figur aufgehen durfe, sondern sie zeigen solle, entspricht dem tatsächlichen vorgang, dass der Schauspieler in zweierlei Gestalt auf der Bthne steht: als Schauspieler und als die dargestellte Figur. Im Brecht-Theater wird die allen Zeiten gemeinsame stillschweigende Ubereinkunft, dass sich das Publikum im Theater befindet und nicht dem wirklichen Leben zusieht, ins Bewusstsein der Zuschauer gebracht. Das Theater wird - den Tatsachen entsprechend - offen als Kunst, als Abbild des Lebens, das bestimmten künstlerischen Gesetzmässigkeiten unterliegt, dargeboten.24 
der Aufbau der Rollen ist also ein sehr langwieriger schopferischer Vorgang. Wie Gisela Bahr und Weber erkannt haben, lasst sich diese Methode kaum in die Vereinigten

Staaten exportieren und es fragt sich, ob Brecht dort therhaupt noch stilgerecht aufgefthrt werden kann:

In dieser Arbeitsweise, der weder zeitlich noch materiell Grenzen gesetzt waren und die fur Brecht ihre Rechtfertigung in dem vom Theater zu leistenden Beitrag zur Diskussion zeitgenossischer Probleme fand, sah Weber das grosste und vermutlich unlosbare Problem bei dem Versuch, Brecht in den USA mit Erfolg aufzufthren. Die therwiegend kommerzielle Basis der amerikanischen Theater verbietet eine auch nur annahernd vergleichbare Vorbereitungszeit ebenso wie die andersgeartete Ausbildung der Schauspieler, die nur personliche Erfahrungen auswertet - was Brecht ausdrticklich vermieden hat. 25

\section{Gestus}

Wenn Brecht immer wieder darauf bestand, dass sich die Problematik der Figur nicht in Monologen auszudrttcken habe, sondern in Taten, so bestand er doch auf dem was er "Haltung" nannte. Diese Haltung konnte, ja musste oft von Episode zu Episode verschieden sein. Sie musste nur fthr den jeweiligen Abschnitt "stimmen."

Die Haltung einer Figur zusammen mit den historischgesellschaftlichen Umständen hatte sich in den einzelnen Szenen im "Gestus" auszudrticken. Brecht definierte seinen Gestusbegriff so:

Unter Gestus soll nicht Gestikulieren verstanden sein: es handelt sich nicht um unterstreichende oder erlauternde Handbewegungen, es handelt sich um Gesamthaltungen. Gestisch ist eine Sprache, wenn sie auf dem Gestus beruht, bestimmte Haltungen 
des Sprechenden anzeigt, die dieser andern Menschen gegentber einnimmt. 26

Anderswo geht er mehr ins Detail:

Unter einem Gestus sei verstanden ein Komplex von Gesten, Mimik und fur gewbhnlich Aussagen, welchen ein oder mehrere Menschen an einen oder mehrere Menschen richten. Ein Mensch, der einen Fisch verkauft, zeigt unter anderm den Verkaufsgestus. Ein Mann, der sein Testament schreibt, eine Frau, die einen Mann anlockt, ein Polizist, der einen Mann pruggelt, ein Mann, zehn Männer auszahlend - in alldem steckt sozialer Gestus...

Ein Gestus kann allein in Worten niedergelegt werden (im Radio erscheinen); dann sind bestimmte Gestik und bestimmte Mimik in diese Worte eingegangen und leicht herauszulesen...

Ebenso können (im stummen Film zu sehen) Gesten und Mimik oder (im Schattenspiel) nur Gesten Worte beinhalten.

Worte konnen durch andere Worte ersetzt, Gesten durch andere Gesten ersetzt werden, ohne dass der Gestus sich dartuber andert. 27

Obwohl Schiller von Gestus noch nichts gehort hatte, ist hier wieder eine grosse Ahnlichkeit der Auffassung zwischen den zwei Sttuckeschreibern zu finden. Die Geste wird zum Gestus erst wenn sie in Bezug auf den Gehalt des Sttickes Bedeutung hat und ist nicht eine durch Theaterkonvention festgelegte Korperreaktion auf eine Gefthlserregung. Ftur Schiller war das einfach schlechtes Theater:

Gewbhnlich haben unsere Spieler ftur jedes Genus von Leidenschaft eine aparte Leibesbewegung einstudiert, die sie mit einer Fertigkeit, die zuweilen gar dem Affekte vorspringt, an den Mann zu bringen wissen. Dem Stolz fehlt das Kopfdrehen auf eine Achsel und das Anstemmen des Ellenbogens selten. Der Zorn sitzt in einer geballten Faust und im Knirschen der Zuhne. Die Verachtung habe ich auf einem gewissen Theater ordentlicherweise durch einen Stoss mit dem Fusse charakterisieren gesehen; die Traurigkeit der Theaterheldinnen retiriert sich hinter ein weissgewaschenes Schnupftuch, und der Schrecken, der noch am ktirzesten wegkommt, wirft sich auf dem năchsten 
dem besten Block seine Bthrde und dem Publikum einen - Stumper vom Halse. 28

Hiezu im Vergleich Brecht:

Die Naturlichkeit der Gesten und Tonfulle darf bei der Auswahl nicht verlorengehen. Es handelt sich nicht um stilisierung. Bei der Stilisierung 'bedeutet' Geste und Tonfall 'etwas' (Furcht, Stolz, Mitleid und so weiter). Ein Gestus, der durch solche Stilisierung zustande kommt, lost den Fluss der Reaktionen und Aktionen der Personen in eine Folge starrer Symbole auf, es entsteht eine Art Schrift mit Schriftzeichen ganz abstrakter Art, und die Darstellung menschlichen Verhaltens wird schematisch und unkonkret. Wenn die Weigel in Die Gewehre der Frau Carrar das Brotbacken (Brechts Betonung) zeigt, so ist dies das Brotbacken der Frau Carrar am Abend der Erschiessung ihres Sohnes, also etwas ganz Bestimmtes, absolut Untransportables. In ihm ist viel vereinigt, das Backen des letzten Brotes, der Protest gegen andere Beschaftigung, wie es das Kumpfen wäre, und zugleich ist das Brotbacken die Uhr fthr den Verlauf des Vorgangs: ihre Verwandlung nimmt die Frist in Anspruch, die fur ein Brotbacken ausreicht. 29

Eine andere Falle, vor der der schauspieler auf der Hut sein muss, ist die Mimik. Der Darsteller "zitiert" seine Rolle, er ist Demonstrant, und Mimik weist darauf hin, dass tbermässige Einfthlung in die Figur stattfand, dass der die Figur interpretierende Schauspieler also in einem Seelenkampf und nicht im klassenkampf steht. 30 Brecht, der immer auch den Einfluss der Technik auf ideelle Phänomene in der Gesellschaft sah, erkannte hier die Wirkung des Opernglases. In seinem Messingkauf sagt er:

Als die stuckeschreiber lange, ruhige Akte mit viel Seele bauten und die Optiker gute Glaser lieferten, nahm die Mimik einen heftigen Aufschwung. Jetzt passierte viel in den Gesichtern, sie wurden zu Seelenspiegeln und mussten darum moglichst still gehalten werden, so dass die 
Gestik verktummerte. Es kam auf die Empfindungen an, die Leiber waren nur Gef asse der Seelen. 31

Wenn man also Gestus ganz allgemein als die jeweils eingenommene Haltung bezeichnen kann, so ist es doch der gesellschaftliche Gestus, der Brecht vor allem interessiert. Sport, zum Beispiel, ist im Westen kein sozialer Gestus, in den kommunistischen Ländern wird er dazu.

Nicht jeder Gestus ist ein gesellschaftlicher Gestus. Die Abwehrhaltung gegen eine Fliege ist zunachst noch kein gesellschaftlicher Gestus, die Abwehrhaltung gegen einen Hund kann einer sein, wenn zum Beispiel durch ihn der Kampf, den ein schlechtgekleideter Mensch gegen Wachthunde zu fthren hat, zum Ausdruck kommt. Versuche, auf einer glatten Ebene nicht auszurutschen ergeben erst dann einen gesellschaftlichen Gestus, wenn jemand durch ein Ausrutschen 'sein Gesicht verlore,' das heisst eine Geltungseinbusse erlitte. Der Arbeitsgestus ist zweifellos ein gesellschaftlicher Gestus, da die auf die Bewalligung der Natur gerichtete menschliche Tutigkeit eine Angelegenheit der Gesellschaft, eine Angelegenheit zwischen Menschen ist. Solange andererseits ein Schmerzgestus so abstrakt und allgemein bleibt, dass er den rein tierischen Bezirk nicht tberschreitet, ist er kein gesellschaftlicher Gestus... Der 'Blick des gejagten Hundes' kann zum gesellschaftlichen Gestus werden, wenn gezeigt wird, wie durch besondere Machenschaften der Menschen der einzelne Mensch auf die tieriscle stufe heruntergedrthckt wird. 32

Es ist Brecht vor allem wichtig, die Sensorien der Leser nicht zu reizen, dafthr aber das Abstrahierungsvermogen der Leser anzuregen. ${ }^{33}$ Der Hauptzweck des Gestus ist immer die Durchdringung gesellschaftlicher Prozesse. Dabei mtissen Phantasie und Erfindung nicht ganz ausgeschaltet werden: Brecht lüsst den Don Quichote von Cervantes gelten, da "er die Uberholtheit des Rittertums und des ritterlichen Geistes zeigt, und doch haben niemals 
Ritter gegen windmuhlen gekumpft." 34

Marianne Kesting illustriert diesen Punkt mit der Szene, in der sich der Hofmeister Lüuffer bei der Majorin vorstellt. Die Szene umfasst nur wenige Worte Text. Luuffer ist gierig, die elende Anstellung zu bekommen. Die Majorin lässt ihn zu seiner aussersten Demutigung ein Menuett vortanzen, damit er seine Befahigung erweise.

$\mathrm{Zu}$ der Perspektive auf menschliche Verhaltensweisen wird die der sozialen entwickelt und ein Verhaltnis in seiner historischen Abhängigkeit dargestellt; zu der Abzeichnung der Zustande liefert Brecht ihre Durchleuchtung und Enththllung. 35

Der Begriff des Gestus will also verstanden sein als eine Handlungsweise, die bedingt ist durch die Position des Individuums in der Gesellschaft. Die Motivierung der Personen erfolgt von aussen her und Brecht had einen eigenen Schauspiel-stil entwickelt, um dieser Prümisse gerecht zu werden. Die Theorie des Gestus kann also vom epischen Charakterbegriff nicht getrennt werden. 


\section{KAPITEL $X$}

DIE NEUE ETHIK: DIE "PRODUKTIVE HALTUNG" ALS ERSATZ FUR DAS TRADITIONELLE MORALSYSTEM

\section{Einleitung}

Wie schon erwahnt wird Charakter gewobnlich als eine Funktion des Menschen in Hinsicht auf feste moralische Prinzipien definiert. Da bei Brecht diese Prinzipien fallen, reagiert der Mensch jeweils auf die Gegebenheiten der augenblicklichen Situation, aber im Hinblick auf die Idealwelt der Nachgeborenen, in der jeder die Möglichkeit haben wird, sich zu seinem Optimum zu entwickeln. Dieses ziel verleiht dem Menschen eine allgemeine "Haltung," die auf Produktivitat gerichtet sein muss. Diese produktive Haltung kommt einem "Seinsentwurf" gleich, der wie eine Skizze im Detail jederzeit verändert werden kann.

Brechts Werk ist im Wesentlichen eine Auseinandersetzung dieser neuen Haltung mit den alten Moralbegriffen. Shen-Te sagt: Ich will mit dem gehen, den ich liebe... ich will nicht nachdenken, ob es gut ist. I Ihre Haltung ist die von Brecht immer als produktiv bezeichnete der Liebe, ihre Zweifel gelten dem Urteil, das sie nach den alten Moralbegriffen ther sich selbst fallen musste. ("Gut" hat hier allerdings den Doppelsinn von moralisch gut und "gut fur mich.") 
In der Dreigroschenoper heisst es: "Ein guter Mensch sein, ja wer wär's nicht gern?" und kurz danach: "Wer mochte nicht in Fried und Eintracht leben? Doch die Verhaltnisse, die sind nicht so." 2 In der stadt Mahagonny darf man endlich alles durfen, was sonst als unmoralisch verboten ist. Diese Kluft zwischen dem burgerlich-moralisch trainierten Gewissen und den praktischen Entscheidungsalternativen ist oft das Hauptproblem von Brechts Figuren, ob man nun an Shen-Te und Johanna denkt oder an die Doppelfigur in den Sieben Todsthden, die sogar gespalten wird. Vom Standpunkt der Volksfiguren Brechts stellt sich die burgerliche Moral als hochtrabend-bedeutungslos oder kleinlich-egoistisch und nur fur die besitzenden Klassen vorteilhaft heraus. Me-Ti sagt im Buch der Wendungen : "Von den Predigern zur Sittlichkeit werden sie von den Verhaltnissen zur Unsittlichkeit angehalten." 3

Brecht sah es als seine Aufgabe, diese Umstände aufzudecken. Er sah sich als Schreiber der Wahrheit. Die Wahrheit war nie abstrakt wie etwa ein Moralkodex, sondern immer konkret. Sie war eine Waffe, die jenen zugespielt werden musste, die sie wirksam machen konnten.

Naturlich muss die Wahrheit im Kampf mit der Unwahrheit geschrieben werden, und sie darf nicht etwas Allgemeines, Hohes, Vieldeutiges sein. Von dieser Art ist ja gerade die Unwahrheit. Wenn von einem gesagt wird, er hat die Wahrheit gesagt, so haben zunächst einige oder viele oder einer etwas anderes gesagt, eine Lthge oder etwas Allgemeines, aber er hat die Wahrheit gesagt, etwas Praktisches, Tatsächliches, Unleugbares, das, um was es sich handelte. 4 
Brecht zielte also darauf hin, die burgerliche Moral als potemkinsches Dorf zu entlarven, indem er die konkrete Wahrheit verbreitete, selbst wenn er dabei das Risiko eingehen musste, feste Richtlinien abzuschaffen und einstweilen jeden Menschen fur seine eigene "produktive Haltung" verantwortlich zu machen. Er gab zu dass dies ein Zwischenstadium war, das im Rtuckblick viel Nachsicht erfordern whrde. Waren diese "finsteren Zeiten" aber vorbei, kam dann die Epoche, wo der Mensch dem Menschen ein Helfer sein wirde ohne weitere Richtlinien fur sein Verhalten zu brauchen.

Sittliches Verhalten in bestimmten Umständen

Die neue Ethik ist kein absoluter Wert, sondern sie ist spezifisch produktiv. Das wird von traditionell eingestellten Menschen oft missverstanden. Neumann kommentiert das Verhalten des Galilei so:

Vom Augenblick seines Widerrufs an gilt denn auch Galilei seinen Schtlern als ein Mann ohne Ethik. Diese Einschätzung seiner Person andert sich erst in dem Moment, da der in den Schoss der Kirche zuruckgekehrte dem einstigen Schtler die heimliche Abschrift seiner "Discorsi" thergibt. Galilei muss furchten durch die Ubergabe des Manuskriptes die "letzten kummerlichen Reste" seiner Bequemlichkeit aufs Spiel zu setzen. Dass er die Abschrift noch nicht vernichtete, begrthdet er mit seiner "Eitelkeit." Aber wie der Widerruf selbst, so verwandelt sich im nun durchbrechenden neuen Galilei-Verständnis des Andrea auch diese Eitelkeit noch in Tugend, ja sie muss im Licht seiner neuen Deutung ihm als ironisches understatement erscheinen:

Andrea: Dies andert alles. Alles. 
Galilei: Ja?

Andrea: Sie versteckten die Wahrheit. Vor dem Feind. Auch auf dem Felde der Ethik waren sie uns um Jahrhunderte voraus.

Galilei: Erlüutere das, Andrea.

Andrea: Mit dem Mann auf der Strasse sagten wir: Er wird sterben, aber er wird nie widerrufen. - Sie kamen zurtlck: Ich habe widerrufen, aber ich werde leben. - Ihre Hande sind befleckt, sagten wir. - Sie sagen: Besser befleckt als leer. Galilei: Besser befleckt als leer. Klingt realistisch. Klingt nach mir. Neue Wissenschaft, neue Ethik.

So ist der, der eine neue Wissenschaft verriet, indem er zugleich gegen eine von ihm selbst als verbindlich erklurte Norm verstiess, in den Augen seines Schtlers mehr als rehabilitiert: er wird als Begrtunder einer "neuen Ethik" verstanden, welche Galilei selbst zu einer gleichsam notwendigen Folge "neuer Wissenschaft" erklurt. Ihre Maximen sind: "Besser befleckt als leer," besser der Widerruf als der Tod. Es ist eine Ethik, nach der, wie es im Buch der Wendungen heisst, "unter sittlichem verhalten... nur ein produktives Verhalten" $z u$ verstehen ist.

Sie ist auf den Effekt gerichtet wie die Wissenschaft, der sie entspricht. Tugenden, welche sich dem praktischen Nutzen entziehen, haben vor ihr als abstrakt $z u$ gelten und entbehren damit der verbindlichkeit...

Einer der Kernsatze des Galilei heisst: "Angesichts von Hindernissen mag die kthzeste Linie zwischen zwei Punkten die krumme sein..."

Dass Galilei die Unterstellung des Schtlers, er sei bei seinem Widerruf im Einklang mit solcherart "Ethik" gewesen, zurtuckweist, bedeutet keineswegs deren generelle Zurtuckweisung durch Brecht. Konnte von einer solchen die Rede sein, so wäre dies die Zurticknahme einer im Werke Brechts beharrlich beschriebenen und modifizierten "Haltung," welche der Dichter immer wieder auch fur sich selbst in Anspruch nahm. Gerhard Szczesny hat sie als "AntiEthik" bezeichnet. 5

Kohlhase sieht dieses Phanomen der Haltung als Waffe, um damit die Menschheit zu verändern. Er meint dass Brecht damit eine moralische Vorurteilslosigkeit gewonnen hat, die nicht mit Unmoral zu verwechseln sei. 6 
Neumann sieht gleicherweise in der Rettung der Discorsi Galileis das positive Resultat einer produktiven Haltung. In spateren Versionen Galileis allerdings liegt der Akzent anderswo.

In den politischen Tendenzstucken findet der zweifelnde Mensch noch Halt und Richtung in der "dritten Sache," the cause, zum Beispiel in der Mutter. Sie verlasst das stille, egoistische hausliche Leben und schliesst sich dem Kampf fur die Gemeinschaft an.

In den spateren stucken (besonders in der spaten Fassung des Galilei), sind die Wegweiser, die dem Menschen gegeben sind, keineswegs so klar.

Wie auch der Existentialismus hauptsächlich unter Kampfbedingungen florierte, so wird auch Brechts Moralphilosophie der "dritten Sache" undeutlich wenn diese dritte Sache nicht mehr klar identifizierbar ist. Ein Mensch wie Galilei trifft dann Entscheidungen, fth die er sich im Nachhinein verdammen muss. Während die "produktive Haltung" anfangs zu diktieren scheint, dass das wissenschaftliche Werk gerettet werden muss, sieht sich Galilei später als Fthrer des Volkes und als solcher hatte er bffentlich Bekenntnis ablegen mussen fur seine Entdeckungen und hatte nicht widerrufen durfen, obwohl ihn das moglicherweise das Leben gekostet häte. Dass bei Galileis erster Entscheidung auch menschliche Schwächen im Spiel waren (unter anderem der von Brecht oft verdammte Egoismus und die Bequemlichkeit), tut hier wenig zur Sache. Galilei verkannte die Prioritaten 
in den möglichen Entscheidungen. Er stand vor einer existentiellen Entscheidung. Er hatte entweder nicht die Kraft oder nicht die Einsicht, die richtige Wahl zu treffen. Dafur gibt es bei Brecht eigentlich keine Absolution.

Die Neuinterpretation des Galileisttheses nahm Brecht nach 1945 vor, als die Atombombe auf Japan gefallen war und die Verantwortung der Wissenschaftler der Menschheit gegentber plotzlich ein akutes Problem stellte. Die Selbstaufopferung fur Ideale war Brecht ansonsten immer schon suspekt gewesen. Als Gymnasiast schrieb er einen Aufsatz mit dem Titel: Dulce et decorum, der unliebsames Aufsehen erregte. Das Martyrium des Sokrates machte im Nachhinein seine Lehren unglaubhaft. ${ }^{7}$ Figuren wie Virginia, die Tochter des Galilei, die sich ftr ihren christlichen Glauben opfert sind immer unsympathisch dargestellt.

Die wie ich und zu gleicher Zeit schrieben, weigerten sich, die wirklichen, allgemein beobachtbaren Vorgänge zu Notiz zu nehmen, und behandelten die Revolution als eine rein geistige, ethische Erhebung der Menschen. Sie begrtussten, dass "der Mensch" sich gegen "das Unrecht" erhob und fthr "die Idee" starb. Dass welche starben, gehorte zu den Interessen der Stthkeschreiber, aber nicht so sehr zu den Interessen derer, die wirklich starben, während sie fur höchst lebendige, genaue und vernunftige Interessen kampften. Sie kampften und riskierten den Tod solange, wie ihre Interessen es verlangten.8

Me-Ti sagte:

Ein schlechtes Leben muss man mehr furchten als den Tod. Ihr musst vielleicht mitunter euer schlechtes Leben riskieren, um ein besseres zu gewinnen, aber den sicheren Tod sollt ihr niemals aufsuchen. 9

Opferbereitschaft ist eine jener Tugenden, die nur 
sehr bedingt zu betatigen sind:

Die alten sittenlehrer bestehen darauf, dass nur die Tugenden zahlen sollen, die um ihrer selbst willen betatigt werden. Karmeh warnt die Arbeiter vor solchen Tugenden und rat ihnen, nur Tugenden zu betatigen, die ihnen Nutzen bringen.10

Weiter warnt Brecht davor, gewisse Tugenden zur Gewohnheit zu machen.

Bei gewissen Ubelständen erhebt sich der Ruf nach gewissen Tugenden. Werden die Tugenden nicht an die Besiegung der Ubelstände gekntipft und bleiben sie allzu lange tbrig, nachdem die Ubelstande besiegt sind, so werden sie oft die Quellen neuer Ubelstande. Das hat man bei der Tapferkeit, Ausdauer, Wahrheitsliebe und Opferbereitschaft oft erlebt.11

Tugenden, so sie therhaupt betatigt werden, sind also an gewisse historische Umstande gebunden und moralische Fragen sind umgekehrt nur mit Zuhilfenahme des historischen Hintergrundes $\mathrm{zu}$ interpretieren. So wäre der Verrat des Wallenstein "von dem Deutschen Schiller" historisch zu sehen, nicht als moralisches Problem, meint Brecht. ${ }^{12}$ In gleicher Weise ist die Bibel historisch zu analysieren:

Joseph von Agypten kauft als Ratgeber des Pharao das Getreide auf, verursacht so eine Hungersnot und beseitigt sie wieder, indem er das Getreide zu hohen Preisen verkauft. Er wird als Wohltater der Menschheit gefeiert. Das Motiv war 8konomisch, nicht moralisch. 13

Wenn ein Land gut verwaltet ist, lost sich die moralische Frage tberhaupt von selbst, meint Brecht:

Wenn der Plan eines Feldzuges schlecht erdacht, sein Ziel zu gross ftur die zur Verfugung stehenden Armeen, seine Ausfuhrung mangelhaft ist, dann ist bei den soldaten besondere Tapferkeit notig. Mit der Tugend besonderer Tapferkeit sollen die soldaten das erreichen, was die Dummeit der Generale nicht erreichen kann. 
Jede Lage hat ihre besonderen sittlichen Gebote, die vor allem beachtet werden mussen und $\mathrm{zu}$ ihrer Beachtung alle jene sonst geltenden Gebote ausser Kurs setzen durfen, die jetzt hindern whrden. Und in einer Lage, wie wir sie geschildert haben, kann nur der sagen, er sei fth die sittlichkeit, der dafur sorgt, dass keine besondere Sittlichkeit notig ist.14

\section{Anderswo fthgt er hinzu:}

Freiheitsliebe, Gerechtigkeitssinn, Tapferkeit, Unbestechlichkeit, Aufopferung, Disziplin, all das ist notig, um ein Land zo umzuformen, dass um zu leben keine besonderen Tugenden mehr nötig sind... Ohne Ungerechtigkeit zu spturen, wird man auch keinen besonderen Gerechtigkeitssinn entwickeln. Ist der Krieg unnotig, ist auch die Tapferkeit unnbtig. Sind die Institutionen gut, muss der Mensch nicht besonders gut sein. Freilich ist ihm dann die Moglichkeit gegeben, es sein zu können. Er kann dann frei, gerecht und tapfer sein, ohne dass er oder andere zu leiden haben. 15

\section{Das burgerlich-traditionelle Moralisieren}

Im Messingkauf 1asst Brecht den Schauspieler sagen:

wie mir das Moralisieren zuwider ist! Den Malchtigen wird der spiegel vorgehalten! Als ob sie sich nicht durchaus gefielen darin! Und als ob, wie schon ein Physiker des siebzehnten Jahrhunderts gesagt hat, die Murder, Diebe und Wucherer nur deshalb morden, stehlen und wuchern, weil sie nicht wissen, wie hasslich das ist! Und die Unterdrthckten werden gebeten, mit sich selber um Gottes Willen endlich Mitleid zu haben! Dieses säuerliche Getränk aus Tränen und Schweiss! Die Bedurfnisanstalten sind zu klein, die Armenhauser haben rauchende ofen, die Minister Rtstungsaktien, die Pfarrer Geschlechtsorgane! Gegen all das soll ich aufreten. 16

Das traditionelle Moralisieren hat drei Schwächen: Es bleibt im Trivialen stecken, es hat keinerlei wirkung auf die Schuldigen und es bietet den Geschadigten nichts als Mitleid. Diese selbe Einstellung war der Hauptfehler des Naturalismus, meint Brecht: 
Das Mitleid war die Hauptstärke der Naturalisten in der Dramatik des ausgehenden 19. Jahrhunderts. In unbezahlbaren Smokings sassen ausgepichte Ausbeuter und deren gewissenloseste Zutreiber auf teuren Sitzen und vergossen Tränen ther das Schicksal der unehelich schwangeren Rose Bernd. Was war geschehen? Zeigte sich die Kreatur der Kreatur gunstig gesonnen? War das Zeitalter der Barbarei zu Ende? Erfand der Morder das funfte Gebot? Nahmen die Unterdrucker, wenigstens fur Minuten therrumpelt, die Interessen der Unterdrtickten wahr? Wenigstens im Geiste? Keineswegs. Man war bei den Naturalisten. Alles, was gezeigt wurde, war die Natur... die gesellschaftlichen Zustande waren als naturliche erklutrt worden.

Der Morder brauchte dem Mord nicht abzuschworren, um sich dem Mitleid hinzugeben, der Mord war so natturlich wie das Mitleid... Der gerthrte Mensch war also durchaus nicht durch ein Kunsterlebnis von seinen Interessen weggelockt worden, im Gegenteil lag die Rthrung in seinem Interesse, denn sie setzte die Bestatigung der Unanderbarkeit einer ihm und nur ihm gunstigen Situation voraus.17

Die Zuschauer, meint Brecht, fanden sich in den moralisierenden Sttlcken im naturalistischen Stil selbst bestatigt, obwohl die Fehler der Gesellschaft krass gezeigt wurden, denn diese Fehler wurden als "naturlich" interpretiert und brachten daher keinerlei moralische Verpflichtung mit sich.

Uber das Mitleid heisst es im Buch der Wendungen:

Me-ti sagte: Mi-en-leh war nicht mitleidig. Wenn er das Elend der Ausgebeuteten und Unterdrtickten sah, entstand in ihm ein Gefthl, das er sogleich in Zorn verwandelte. Das gleiche Gefthl wird bei unwissenden Naturen zum Mitleid. Es ist das eine dumpfe Wehmut, der Verzweiflung ahnlich. Mitleid, sagte Mi-en-leh, ist das, was man denen nicht versagt, denen man Hilfe versagt... 18

Gefthlsbewegungen sind zu prthen, "halt sich doch immer noch der Aberglaube an die echten und ewig gleichbleibenden Gefthle des Menschen." Wie können Gefthle etwas 
Ursprtungliches sein, wenn sie so leicht zu erzeugen und $z u$ verăndern sind?

Die Quelle, aus der unsere Gefthle kommen, ist ebenso verschmutzt wie die unserer Urteile; sie ist nämlich ebenso zugänglich den Anschlagen der Menschen und wird also von uns selber und anderen immerfort verunreinigt.19

Das ausserordentlich suspekte Gefthl des Mitleids hilft also, das Gewissen zu beschwichtigen, ohne in irgendeiner Weise zum eingreifenden Handeln zu zwingen. Der Zuschauer vergiesst geniesserisch Tränen, ohne sich im thbrigen angesprochen zu fthlen.

Wie versucht dagegen Brecht, den Zuschauer zu engagieren, zum eingreifenden Denken zu bringen? Zwei seiner wirksamsten Mittel sind erstens die Perversitat der konventionellen moralischen Dikta aufzuzeigen, und zweitens, den Zuschauer thber sich selbst zum Lachen zu bringen.

Ein Beispiel fthr die erste Methode ist die Wlassowa der Mutter. Der Sohn, der immer weniger bezahlt bekommt, versucht seine Mutter dazu zu bringen, bei einem Streik zu helfen. Die verzagte alte Frau versagt ihm das anfangs, da sie in ihrem ganzen Leben noch nie etwas Gewalttätiges getan hatte und jetzt auf ihre alten Tage auch nicht damit anfangen wollte. Die "moralische" Tradition, sich der Autoritat zu fugen, beschränkt also die Handlungsfreiheit des kleinen Mannes, der sich ein reines Gewissen bewahren möchte. Die Perversitat der Situation liegt in der offensichtlichen Unmoral der Besitzer der Produktionsmittel und dem Versuch der Arbeitnehmer, so lang wie moglich keine 
moralischen und staatlichen Gesetze zu tbertreten. Der Zuschauer muss darauf mit Emporung reagieren.

Giehse weist darauf hin, dass der Humor eine ebenso wirksame Waffe sein kann wie die Emporrung.

Eingängige Formeln wie "Erst kommt das Fressen, dann kommt die Moral" haben dem Bthrger, tonen sie von der Bthne ins Parkett hinein, noch allemal eingeleuchtet. Mit ihnen war indessen keine direkte Provokation beabsichtigt, oder doch jedenfalls nicht in erster Linie, mochte trotzdem sich aufregen, wer wollte. Vielmehr wurde der, dessen Tugend-Imperative so streng sind, dass er im Leben nicht "durfen darf," was er gern mochte, verleitet, jetzt im Theater aus der ihm lastigen Rolle $\mathrm{zu}$ schltpfen und mit dem sich zu identifizieren, was er seiner Ideologie folgend verdammen musste. 20

Brecht hofft, dass im Augenblick der Erntuchterung, durch verfremdende Einlagen herbeigefthrt, der Burger kritische Einsicht in sein eigenes Verhalten gewinnt.

Werte und Grundsätze der neuen Ethik

Whhrend ein Kernsatz der Klassiker lautet: Edel sei der Mensch, hilfreich und gut, heisst Brechts oberstes Gebot: Der Mensch sei produktiv. Nur auf diesem Weg findet er persolnliches Gltick und sorgt fth das Gltick der Gemeinschaft. Im Kaukasischen Kreiderkreis wird das strittige Tal denen zugesprochen, "die fthr es gut sind." Auch Grusche bekommt das Kind, das ihr nach bthrgerlichem Recht nicht gehort, weil sie eben fur es gut ist. Das Gerichtswesen wird umgekrempelt nach dem Grundsatz der Produktivitat. Paragraphen und Urteile veralten, aber eine auf Produktivität gerichtete Haltung bleibt immer gerecht. So heisst es 


\section{im Buch der Wendungen:}

Wieviel konnte es (das Volk) von ihm (Kungfutse) brauchen, als es seine Haltung nachahmte! Seine Urteile... waren langst ungerecht geworden, hätte man sie wiederholt, aber seine Haltung war die der Gerechtigkeit.2I

Wenn die Idee der Haltung die Funktion der festen Grundsatze tbernimmt, bedeutet das, dass der Mensch ununterbrochen neue Information aufnehmen muss, um seine Haltung den gegebenen Umständen anzupassen. Er befindet sich im permanenten Zustand des Lernens. Dorothee sollle sieht dies so:

Das Lernziel ist... identisch mit dem Lernprozess. Die Erkenntnis besteht darin: zu verhindern, dass etwas fertig wird... Lernen bedeutet fthr Brecht, sich selber in seinen Möglichkeiten erfahren und die eigene Ohnmacht zu tberwinden. Lernen entspricht dem revulitionaren Bewusstsein, so wie fur das burgerliche Bewusstsein bei Brecht das Kennen charakteristisch ist. Lernen ist das Gegenteil von Kennen, ein Lernender sein das Gegenteil von einem Kenner... Menschenkenntnis ist nur notig, wo Ausbeutung im Spiel ist. Denken heisst verändern... Einen Menschen kennen, heisst zugleich, ihn beherrschen.

Sollle zitiert eine Keunergeschichte, in der eine liebende Frau die Unberechenbarkeit ihres Mannes in "lernender Haltung" hinnimmt. "Aus der Kennerschaft ist die Bereitschaft des permanenten Lernens geworden." 22

Zum Verhaltnis der Liebe, um es produktiv zu machen, muss der Mensch sowohl vom Standpunkt des Lernenden als auch dem des Lehrenden beitragen. Es ist die Verantwortung des Partners, nicht nur zu lernen sondern auch dem anderen ein "Bildnis" $z$ machen, nach dem er sich entwickeln kann. (Max Frisch hat sich auch mit diesem Thema auseinandergesetzt, 
ist aber $\mathrm{zu}$ dem Schluss gekommen, dass Bildnisse immer.

hemmend und schadlich seien.)

Wenn man den Menschen liebt, kann man aus seinen beobachteten Verhaltensarten und der Kenntnis seiner Lage solche Verhaltensarten ftr ihn ableiten, die fur ihn gut sind. Man kann dies ebenso wie er selber. Aus den vermutlichen Verhaltensarten werden so wtinschbare. $\mathrm{Zu}$ der Lage, die sein Verhalten bestimmt, zahlt sich plotzlich der Beobachter selber. Der Beobachter muss also dem Beobachteten ein gutes Bildnis schenken, das er von ihm gemacht hat. Er kann Verhaltensarten einftugen, die der andere selber gar nicht fande, diese zugeschobenen Verhaltensarten bleiben aber keine Illusionen des Beobachters; sie werden zu Wirklichkeiten: Das Bildnis ist produktiv geworden, es kann den Abgebildeten veründern, es enthalt (ausfthrbare) Vorschläge. Solch ein Bildnis machen heisst man lieben.23

Dieses Prinzip, auf Goethes Faust angewendet, ergibt

folgende Interpretation:

Faust hat sich aus dem leidvollen widerspruch zwischen "rein geistigen" und "rein sinnlichen" Begierden gerettet, und zwar mit Hilfe des Teufels. In der "rein sinnlichen" sphäre (der Liebesgeschichte), stosst sich Faust an der Umwelt, vertreten durch Gretchen, und muss sie vernichten, um sich zu retten. Die Lbsung des Hauptwiderspruchs kommt am Ende des ganzen Sttuckes und macht erst die Bedeutung und stellung der minderen Widersprtiche klar. Faust muss seine rein konsumierende, parasiture Haltung aufgeben. In der produktiven Arbeit fur die Menschheit vereinigt sich geistige und sinnliche Tat, und in der Produktion von Leben ergibt sich der Genuss am Leben.

Zurtlckkehrend zu unserer Liebesgeschichte, konnen wir sehen, dass eine Heirat, wie spiessig immer, unmoglich dem Genius, widersprechend seiner Laufbahn, doch in relativem Sinn das Bessere, da Produktivere gewesen wäre, denn dies wäre die zeitgegebene Vereinigung, in der die Geliebte hatte entwickelt anstatt vernichtet werden können. Faust wäre dann allerdings kaum Faust, bliebe im (wie sich plotzlich ergibt) Kleinen stecken und so weiter und so weiter. 24 
Trotz einigen zögerns whrde Brecht also das Genie, den Helden, den "Charakterkopf" aufopfern fur das gute, produktive Leben im Kleinen. Unter optimalen Umständen können die Liebenden sogar den grossen Einzelnen ersetzen, denn

Den Besten gelingt es, ihre Liebe in volligen Einklang mit anderen Produktionen zu bringen; dann wird ihre Freundlichkeit zu einer allgemeinen, ihre erfinderische Art zu einer Vielen ntutzlichen und sie unterstutzen alles Produktive. 25

Die Produktion durch die Liebe schlägt also Kreise, die immer mehr Menschen einschliessen.

Was Me-ti sich Gutes erwartete, wenn zwei Hünde, etwa von Mann und Frau, sich bei einer gemeinsamen Arbeit, beim Eimertragen, berthren, das erwartete sich Mi-en-leh fur junge volker, wenn sich ihre Hände beim Treiben des Rades der Geschichte berthren. 26

Brecht betonte noch andere zwischenmenschliche Verhaltnisse als unterstutzungswhrdig und wertvoll. Das grundlegendste davon ist wohl die Mutterschaft, die in vielen von Brechts Stucken eine bedeutende Rolle spielt und der Idee des "Naturrechts" am nächsten kommt. Hier ist zu denken an Grusche, Mutter Courage, Shen-te, die Wlassowa, Frau Carrar, etc. Der Bestand der Familie war fur Brecht auch wichtig:

Fast alle burgerlichen Institutionen, fast die ganze Moral, beinahe die gesamte christliche Legende grthden sich auf die Angst des Menschen, allein zu sein, und ziehen seine Aufmerksamkeit von seiner unsăglichen Verlassenheit auf dem Planeten, seiner winzigen Bedeutung und kaum wahrnehmbaren Verwurzelung ab. Beinahe alle denkbaren Tragodien; die sich im Bezirk der Familie abspielen, alle Verbrechen darin sind 
gutzuheissen (dramatisch zu verwerten), da sie den Bestand der Familie festigen...27

Die Familie ist als Zentrum der Produktion zu betrachten.

Werden die Menschen unfahig, zu der Produktion beizutragen, sind sie von einflussreichen stellungen auszuschliessen. Sie verdienen aber Schonung. Zu dieser Gruppe gehuren besonders die alten Leute. "Der Nutzen, den sie zu geben vermögen, ist schwer zu gewinnen, der Schaden schwer abzuhalten. Sie mussen mit besonderer Freundlichkeit behandelt werden."28 (Freundlichkeit und Hळflichkeit gehorren fthr Brecht zur angemessenen Haltung den Besiegten, Schwachen gegentber.)

Schliesslich hat das Individuum innerhalb der Gesellschaft auch noch selbst einen Glticksanspruch, ja eine Verpflichtung dazu:

Gegen die Eigenliebe kann man nichts haben, wenn sie sich nicht gegen andere richtet. Wohl aber kann man gegen den Mangel an Eigenliebe etwas haben. Schlechte Zustande kommen sowohl von der Eigenliebe der einen wie von dem Mangel an Eigenliebe der andern. Wer sich nicht genug liebt; wer sich nicht die Mittel verschafft, die ihn liebenswert machen... der verpestet das Gemeinwesen mit seinem Elend.29

Obwohl der einzelne also dazu verpflichtet ist, an seinem eigenen Gluck mitzuarbeiten, liegt die Hauptverantwortung doch bei der Gemeinschaft. Dorothee solle kommentiert eine Keunergeschichte folgendermassen:

"Herr K. sah eine Schauspielerin vorbeigehen und sagte: Sie ist schon. Sein Begleiter sagte: Sie hat neulich Erfolg gehabt, weil sie schon ist. Herr $\mathrm{K}$. argerte sich und sagte: Sie ist schön, weil sie Erfolg gehabt hat." 
Fthr Herrn K. gibt es noch eine andere Art von Schonheit als die naturliche, gegebene. Sie ist es, die ihn in der Geschichte von der Schauspielerin interessiert. Der burgerliche Begleiter Herrn K.s vollzieht in seinem Denken den Verwertungszusammenhang, wenn er den Erfolg auf die Schonheit zurtickfthrt, Herr K. dagegen bemerkt die Schonheit als erster, und zwar unabhangig vom Verwertungszusammenhang. Er ist darum genbtigt, eine andere Logik als die der Kapitalverwertung aufzustellen, eine Logik, in der die Geschichte eines Menschen, seine Erfolge und Misserfolge nicht von seinen naturlichen Anlagen herrthren, wo vielmehr ungekehrt auch das, was uns zunachst wie ein stllck Natur erscheint, eine Folge erlebter Geschichte darstellt. Die Geschichte ündert die Natur. Schonheit ist nicht ein vorgegebenes und darum der Verdinglichung preisgegebenes Faktum, sondern sie ist dem Menschen zur Verwirklichung aufgegeben, oder, weil diese Formulierung vielleicht idealistisch missverstanden werden konnte (als sei es Sache des einzelnen, der zu werden, der er ist): die Schonheit des einzelnen ist allen
aufgegeben. 30

(Die Schonheit und das Gesicht stehen bei Brecht auch anderswo als pars pro toto: Me-ti: "Der Erfolg macht schon, grosszthigig und sicher, zumindest macht er ein Gesicht. Der Misserfolg verwischt ein Gesicht." Ahnlich ist die "Ausloschung des Gesichts" in der Massnahme.)

Brecht sieht also die "grosse Produktion" und die Solidaritat der Einzelnen innerhalb der Gemeinschaft als Grundlage fur küntige bessere Zeiten. Jedoch kann man die Figur des Weisen im Werk Brechts nicht ignorieren. In seinem Gedicht an die Nachgeborenen schreibt Brecht:

Ich wäre gerne auch weise.

In den alten Btichern steht, was weise ist:

Sich aus dem Streit der Welt halten und die kurze Zeit

Ohne Furcht verbringen

Auch ohne Gewalt auskommen

Boses mit Gutem vergelten 
Seine wthsche nicht erfullen, sondern vergessen Gilt fthr weise.

Alles das kann ich nicht:

Wirklich, ich lebe in finsteren Zeiten. ${ }^{31}$

Neumann, der sich speziell mit der Figur des Weisen

bei Brecht beschaftigt hat, sagt hiezu:

Die Weisheitsdefinition der "alten Bticher" bestimmt den Platz des Weisen an der Peripherie der Gesellschaft. Nur fern vom "streit der Welt" wäre auch die Furcht ferne und mit ihr der Zwang zu eigener Gewalttat; dort am ehesten wäre das Vergessen der eigenen wthnsche moglich, der affektlose Gleichmut des Unbeteiligten, die stoische Apatheia. Brechts Ohnmachtsbeteuerung rthckt mit dem Hinweis auf den zustand der eigenen historischen Epoche solche Art Weisheit in die Nachbarschaft sozialer Versulumnisse. 32

Neumann scheint hier zu weit zu gehen. Der weise Lehrer, dessen grösster Erfolg es ist, sich selbst therflussig zu machen, war ein Idealbild Brechts. Die Figur des Lao-tse wird allgemein als ein Selbstportrait Brechts betrachtet. Wenn Brecht dieser seine Figur gegentber nicht vorbehaltslos scheint, so ist es, weil die finsteren Zeiten noch nicht vorbei sind, wir noch im Kampf um das bessere Leben stehen und wir es uns vorderhand noch nicht leisten können, weise zu sein.

Der Weise ist gewaltlos. Neumann entwickelt dieses Thema zum Extrem indem er sagt, dass die, welche die Gewalt vermeiden, weise genannt werden können. "Das Harte unterliegt," heisst es im Lao-tse. ${ }^{33}$ Mehrere Keunergeschichten beschaftigen sich auch mit diesem Standpunkt, zum Beispiel die folgende:

Als Herr Keuner, der Denkende, sich in einem Saale vor vielen gegen die Gewalt aussprach, 
merkte er wie die Leute vor ihm zurtuckwichen und weggingen. Er blickte sich um und sah hinter sich stehen - die Gewalt.

"Was sagtest du?" fragte ihn die Gewalt.

"Ich sprach mich fthr die Gewalt aus," antwortete Herr Keuner.

Als Herr Keuner weggegangen war, fragten ihn seine Schtler nach seinem Rthckgrat. Herr Keuner antwortete: "Ich habe kein Rtickgrat zum Zerschlagen. Gerade ich muss langer leben als die Gewalt." 34

Für den Durchschnittsmenschen ist Uberstehn vielleicht nicht alles, aber doch der erste schritt zum eventuellen Sieg. Fthr die, die die Fthrung zu tbernehmen bereit sind, heisst die Losung allerdings oft anders. "Noch ist es uns nicht vergönnt, nicht zu töten," steht in der Massnahme. ${ }^{35}$ In den Tagen der Kommune sagt Langevin: "In diesem Kampf gibt es nur blutbefleckte Hünde oder abgehauene Hünde." 36 Anderswo in der Massnahme, einem der Lehrstlucke, heisst es: "Welche Niedrigkeit begingest du nicht, um die Niedrigkeit auszutilgen? Könntest du die Welt endlich verändern, woftur wärest du dir zu gut?" 37 In den Politischen Schriften fuhrt Brecht weiter aus: "Gute bedeutet heute, wo die nackte Notwehr riesiger Massen zum Endkampf um die Kommandohthe wird, die Vernichtung derer, die die Gthte unmoglich machen." 38

Die Haltung, die Brecht vorschreibt, erfordert also zundchst den passiven, oft opportunistisch scheinenden Widerstand um das Uberleben zu garantieren. Im Endkampf aber sind alle Mittel der Gewalt recht, um den Endzweck eines besseren Lebens herbeizufthren. Neumann fragt hier, ob Brecht dessen angeklagt werden könne, einen anti-ethischen 
Rigorismus zu formulieren. "Ja," meint er, "wenn es denn fur niedrig gelten soll, die Niedrigkeit auszutilgen." Er fragt weiter:

Wer wäre berechtigt, das Programm der Kommunisten, das hier sich niederschlägt, "anti-ethisch" zu nennen? (Sczcesny). Freilich gelangt, wer die Niedrigkeit um einer neuen Humanitat willen auf sich nimmt, "oft hart and die Grenze einer neuen Inhumanitat." (Hans Mayer).' Diese Grenze zu tuberschreiten, ist das standige Risiko eines jeden, der sich zu einer "Haltung" versteht. 39

\section{Die Brechtsche Zukunftsvision}

"Wenn es soweit sein wird, dass der Mensch dem Menschen ein Helfer ist, gedenkt unser mit Nachsicht," heisst es in den Nachgeborenen. 40 Die Zeit wird kommen, wo niemand den anderen mehr ausbeuten wird, wo alle genug Freizeit haben werden, sich auf den Gebieten der Kultur, Kunst und Wissenschaft zu bilden, wo sinnesfreuden erlaubt sein werden und die niedrige Arbeit zur schöpferischen Produktion geworden sein wird. Die Gesellschaft wird es dem Menschen moglich machen, "sich zu produzieren," 41 und sich gegenseitig aufzubauen. 42 Allerdings leben wir noch in finsteren zeiten, die Gewalttaten nicht ausschliessen.

Diese paradiesische Zukunftsvision ist von mehreren Seiten angegriffen worden. Hans Magnus Enzensberger fragt in seinem Gedicht Weiterung: "Wer soll da noch auftauchen aus der Flut wenn wir darin untergehen?" Und er antwortet: "Keine Nachgeborenen, keine Nachsicht, nichts weiter." 43 Hans Mayer meint, dass eben der nachbrechtische Sachverhalt diese Zukunftsvision als Wolkenspiegelung herausgestellt 
hat.

Kolhase wendet ein, dass Brechts Erwartungen ständig bedroht seien durch die Möglichkeit des Scheiterns.

Sie sind wie alle Utopien in permanenter Schwebe, und deshalb nicht enttäuschbar... Daraus wird deutlich, dass die Revolution gar nicht verwirklicht werden darf, wenn der Charakter der Utopie im Marxismus, den er wesensgemass notig hat, nicht verlorengehen soll. Da das wahre Wesen des Menschen immer ther ihn hinaus weist und niemals mit seinem wirklichen Wesen zusammenfullt, da die Existenz und die Essenz des Menschen nie identisch sein können, entsteht die Frage, ob die Entfremdung des Menschen je aufgehoben werden kann. Das Problem deutet auf die religiose Natur marxistischer Heilserwartungen... hin. Ihm liegt das gnostische Erlebnis zugrunde, wonach die Welt als Fremde erfahren wird...45

Kohlhase zitiert weiter einen Ausspruch Thomas Manns aus seiner Frankfurter Rede im Goethejahr; Mann sprach von der "Verderbnis der Idee durch ihre Verwirklichung." Kohlhase meint, dass Brecht die Unausfthrbarkeit seiner Utopie einsah und daher nicht zu den pragmatischen Marxisten, sondern $z u$ den Existentialisten zu zahlen sei, deren Glauben keine Vision einer besseren Zukunft einschliesst.

Jost Hermand erkennt auch Brechts Zweifel an der Ausfuhrbarkeit seiner Zukunftsideen, "doch er gab sich wenigstens die Mthe, etwas von jener Zielvorstellung anzudeuten, ohne die all unser gegenwärtiges Tun seine innere Sinngebung einbtissen whrde," räumt er ein. Seine zuktunftige Gesellschaft dient also als Idealbild, eine Richtlinie ftur die heutige "Haltung" darstellend. 46

Nach Ubersiedelung in die D.D.R. vertritt Brecht dann 
die These, nicht ständig auf bessere Zeiten zu hoffen, sondern die lang ersehnte Utopie im Hier und Jetzt beginnen zu lassen. Jost Hermand zitiert Brecht:

Warum, fragten wir uns

Das goldene Zeitalter noch aufschieben?

Wir leben doch nicht ewig.

Und Brecht gibt darauf im selben Gedicht die apodiktisch-optimistische Antwort, um sich und die anderen D.D.R.-Bewohner in ihrem Lebenswillen zu besturken:

Nimm Platz am Tisch, du hast ihn doch gedeckt. Von heute ab wird auch die das Kleid tragen, die es gendht hat.

Heute, mittag um zwolf Uhr Beginnt das goldene Zeitalter. 
FUSSNOTEN

Kapitel I

${ }^{1}$ Max Frisch, Erinnerungen an Brecht (Friedenauer Presse, Verlag der Wolf's Bthcherei, 1968), S. 18.

2 Norbert Kohlhase, Dichtung und politische Moral: Eine Gegentuberstellung von Brecht und Camus (Mthnchen: Nymphenburger Verlagshandlung, 1965), S. 44.

${ }^{3}$ Bertolt Brecht, Schriften zur Literatur und Kunst 2 (Frankfurt: Suhrkamp Verlag, 1967), s. 145.

Kapitel II

${ }^{1}$ Brockhaus Enzyklopaddie, dritter Band (Wiesbaden: F. A. Brockhaus, 1967), S. 694 .

${ }^{2}$ Das grosse Duden Lexikon, zweiter Band (Mannheim: Bibliographisches Institut, Lexikon Verlag, 1965), S. 87.

${ }^{3}$ Jakob und Wilhelm Grimm, Deutsches worterbuch (Leipzig: S. Hirzel Verlag, 1860), S. 611.

4 worterbuch der Psychologie, Wilhelm Hehlmann, Hsgb. (stuttgart: Alfred Körner Verlag, 1974), S. 72 .

5 Wilhelm Reich, Character Analysis (New York: The Noonday Press, a subsidiary of Farrar, Strauss and Cudahay, 1949), S. 145 .

6 Nandor Fodor Hsgb. , Freud: Dictionary of Psychoanalysis (Westport, Conn.: Greenwood Press Publishers, 1975), s. 21 .

${ }^{7}$ Gregory A. Kimble and Norman Garmezy, Principles of General Psychology (New York: The Ronald Press Co., 1963), S. 89.

${ }^{8}$ Gardner Lindsey et al., Psychology (New York: Worth Publishers Inc., 1975), S. 485.

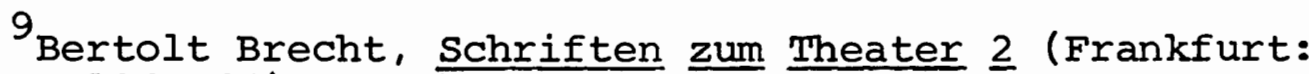
suhrkamp 1963-64), S. 270 . 
${ }^{10}$ Charles Walcutt, "What Is Character?" aus Man's Changing Mask: Modes and Methods of Characterization in Fiction (Minneapolis: University of Minnesota Press, 1966), S. $5 f f$.

${ }^{11}$ Kohlhase, Dichtung und politische Moral, s. 134.

\section{Kapitel III}

$I_{\text {Hans Mayer, Deutsche Literatur seit Thomas Mann }}$ (Reinbek bei Hamburg: Rowohlt Verlag, 1967), S. 29 .

${ }^{2}$ Siegfried Mews, "Brechts dialektisches Verhaltnis zur Tradition": Bearbeitung des Michael Kohlhaas von Kleist, Brecht Jahrbuch 1975, John Fuegi Hsgb. (Frankfurt: Suhrkamp Verlag, 1975), S. 63.

3 Bertolt Brecht, Politische Schriften (Frankfurt: Suhrkamp Verlag, 2. Aufl., 1972), S. 52 .

$4_{\text {Ebenda, S. } 59 .}$

$5_{\text {Kathe Rthlicke-Weiler, Die Dramaturgie Brechts: }}$ Theater als Mittel der Verduderung (Berlin: Henschel Verlag, 2. Aufl., 1968), S. 25.

Ebenda, S. 169 .

${ }^{7}$ Friedrich Schiller, Die Räuber (München: Deutscher Taschenbuchverlag, 1965), s. 141-146.

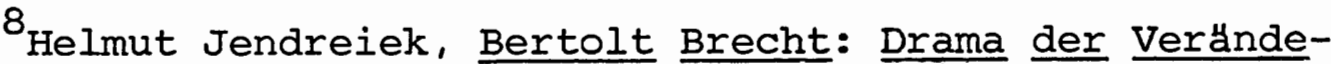
rung (Dthsseldorf: August Bagel Verlag, 1969), S. 32 lf.

9 Bertolt Brecht, "Kleines Organon fur das Theater," aus Heft 12 der Versuche (Berlin: Suhrkamp Verlag, 1958), S. 121 .

\section{Kapitel IV}

${ }^{1}$ Bertolt Brecht, Schriften zur Literatur und Kunst 2 (Frankfurt: Suhrkamp Verlag, 1967), S. 83.

2 Bertolt Brecht, Schriften zum Theater 2 (Frankfurt: Suhrkamp Verlag, 1963), S. 270.

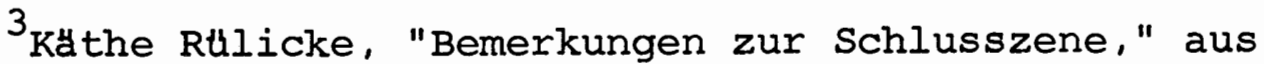
Materialien zu Brechts 'Leben des Galilei,' Werner Hecht, Hsgb. (Frankfurt: Suhrkamp Verlag, 1963), S. 110. 
${ }^{4}$ Bertolt Brecht, Schriften zum Theater, ausgewhhlt von Siegfried Unseld (Berlin: Suhrkamp Verlag, 1957), S. 151.

5 Bertolt Brecht, Schriften zum Theater 5 (Frankfurt: Suhrkamp Verlag, 1963), S. 106.

6 Bertolt Brecht, Schriften zum Theater, zusammengestellt von Siegfried Unseld (Berlin: Suhrkamp 1957), S. 242.

7 Bertolt Brecht, Schriften zum Theater $\underline{5}$ (Frankfurt: Suhrkamp Verlag, 1963), S. 103.

8 Norbert Kohlhase, Dichtung und politische Moral: Eine Gegentberstellung von Brecht und Camus (Mthnchen: Nymphenburger Verlagshandlung, 1965), S. 134.

9 Ebenda, S. 55.

10 Hans jtirgen Rosenbauer, Brecht und der Behaviorismus (Bad Homburg V.D.H.: Verlag Gehlen, 1970), S. 37.

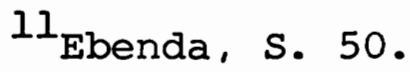

${ }^{12}$ Walter H. Sokel, "Brecht's Concept of Character," Comparative Drama, Fall 1971, S. 180.

13 Bertolt Brecht, Schriften zur Literatur und Kunst 2 (Frankfurt: Suhrkamp Verlag, 1967), S. 18lff.

14 Ebenda, S. 198.

15 Ebenda, S. 199.

${ }^{16}$ Reinhold Grimm, "Notizen zu Brecht, Freud und Nietzsche," aus Brecht-Jahrbuch 1974 (Frankfurt: Suhrkamp Verlag, 1975), S. 34-52.

17 Ebenda, s. 31 .

\section{Kapitel V}

${ }^{1}$ Bertolt Brecht, Schriften zum Theater $\underline{5}$, s. $39 f$.

2 Ebenda, S. 106.

3 Ebenda, S. 108 .

4 Ebenda, S. 62 .

${ }^{5}$ Kohlhase, Dichtung und politische Moral, s. 28. 
${ }^{6}$ Rolf Geissler, Zur Interpretation des modernen Dramas (Frankfurt: Verlag Moritz Diesterweg, not dated),

Kapitel VI

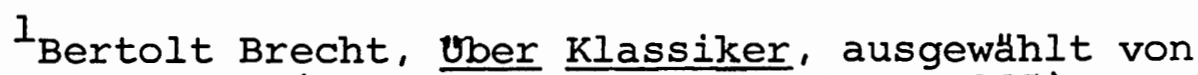
Siegfried Unseld (Frankfurt: Insel Verlag, 1965), S. 136.

2 Bertolt Brecht, "Anmerkungen zur Dreigroschenoper," aus Stthcke ftur das Theater am Schiffbauerdamm, 1. Band (Berlin und Frankfurt: Suhrkamp Verlag 1958), s. 158.

3 Bertolt Brecht, Schriften zum Theater $\underline{5}$, s. 179.

4 Ebenda, S. $179 f f$.

5 Bertolt Brecht, Schriften zur Literatur und kunst 3 (Frankfurt: Suhrkamp Verlag, 1967), S. $196 f$.

${ }^{6}$ Manfred Wekwerth, Theater in Veranderung (Berlin: Aufbauverlag 1960), S. $16 \overline{6}$.

${ }^{7}$ Kohlhase, Dichtung und politische Moral, S. 56.

8 Bertolt Brecht, "Die Ausnahme und die Regel," aus Stlicke ftur das Theater am Schiffbauerdamm, 3. Band (Berlin und Frankfurt: Suhrkamp Verlag, 1957), S. 187.

9 Kohlhase, Dichtung und politische Moral, s. 20.

10 Bertolt Brecht, Geschichten (Frankfurt: Suhrkamp Verlag, 1962), S. 173 .

${ }^{11_{\text {Ebenda, }}}$ S. 195.

12 Bertolt Brecht, Schriften zum Theater, Hsgb. Unseld, S. $156 f$.

13 Bertolt Brecht, Schriften zum Theater 5, S. 247 .

14 Bertolt Brecht, Schriften zum Theater 1 (Frankfurt: Suhrkamp Verlag, 1963), S. 221.

15 Ebenda, S. 221 .

16 Ebenda, S. 255.

17 Bertolt Brecht, Schriften zum Theater 2 (Frankfurt: Suhrkamp Verlag, 1963), S. 143 . 
Kapitel VII

${ }^{1}$ Jendreick, Drama der Verüderung, s. $338 \mathrm{f}$.

2 Rainer Taèni, Drama nach Brecht (Basel: Basilius Presse, Basler Druck und Verlagsanstalt, 1968), S. 44.

3 Ebenda, s. 2 .

${ }^{4}$ Peter Christian Giese, Das "Gesellschaftlich-Komische": Zu Komik und Komodie am Beispiel der Stúcke und Bearbeitungen Brechts (Stuttgart: Metzlersche Verlagsbuchhandlung, 1974), S. 82 .

${ }^{5}$ Bertolt Brecht, Kleines organon, S. 120.

\section{Kapitel VIII}

${ }^{l}$ Bertolt Brecht, Kleines organon, S. 132.

${ }^{2}$ Giese, Das "Gesellschaftlich-Komische," s. 96.

3 Hans Mayer, Deutsche Literatur seit Thomas Mann (Reinbek bei Hamburg: Rowohlt Verlag, 1967), S. 32.

${ }^{4}$ Giese, Das "Gesellschaftlich-Komische," s. 97.

5 Ebenda, s. 95.

6 Bertolt Brecht, "Anmerkungen zur Massnahme," aus sttucke fur das Theater am Schiffbauerdamm, 2. Band (Berlin und Frankfurt: Suhrkamp Verlag, 1955), S. 311.

\section{Kapitel IX}

${ }^{l}$ Bertolt Brecht, Schriften zum Theater 1, s. 31 .

${ }^{2}$ Bertolt Brecht, Schriften zur Literatur und kunst ${ }^{3}$, S. 95 .

3 Ebenda, s. 100 .

4 Ebenda, S. 103.

${ }^{5}$ Bertolt Brecht, Schriften zum Theater 5, s. 70.

6 Ebenda, S. 73.

7 Ebenda, s. 76 . 
8 Ebenda, s. 79 .

${ }^{9}$ Bertolt Brecht, Schriften zur Literatur und Kunst 3 . S. $173 f$.

10 Ebenda, S. 171.

ll Wolfgang Roth, "Working with Bertolt Brecht," aus Brecht heute - Brecht Today, Jahrbuch der internationalen Brecht Gesellschaft, Jahrgang 2, Reinhold Grimm et al.. Hsgb. (Frankfurt: Athenuum Verlag, 1972), S. 132.

12 Kathe Rulicke-Weiler, Die Dramaturgie Brechts: Theater als Mittel der Veranderung, 2. Aufl. (Berlin: Henschel Verlag, 1968), S. 164.

13 Bertolt Brecht, Schriften zum Theater 6 (Frankfurt: Suhrkamp Verlag, 1964), S. 196.

${ }^{14}$ Bertolt Brecht, Schriften zum Theater 5, s. 142 .

15 Ebenda, S. 114.

${ }^{16}$ Rulicke, Dramaturgie Brechts, s. 174.

17 Ebenda,

18 Bertolt Brecht, Schriften zum Theater 4 (Frankfurt: Suhrkamp Verlag, 1963), S. 21 .

${ }^{19}$ Ebenda, S. 22 .

20 Ebenda, S. 47-8.

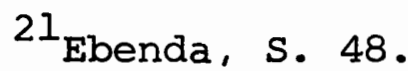

22 Bertolt Brecht, Schriften zum Theater 5 , s. 116.

23 Bertolt Brecht, Schriften zum Theater 2, s. 21 .

${ }^{24}$ Rtulicke, Dramaturgie Brechts, s. 163.

${ }^{25}$ Gisela Bahr, "Brecht in den siebziger Jahren: Themen und Thesen," aus Brecht heute - Brecht Today, Jahrbuch der internationalen Brecht Gesellschaft, Reinhold Grimm et al., Hsgb. (Frankfurt: Athenäum Verlag, 1972), S. 24.

${ }^{26}$ Bertolt Brecht, Schriften zum Theater 3 (Frankfurt: Suhrkamp Verlag, 1963), S. 281 .

27 Bertolt Brecht, Schriften zum Theater 4 (Frankfurt: Suhrkamp Verlag, 1963), S. 3lf. 
${ }^{28}$ Friedrich Schiller, "Uber das gegenwärtige teutsche Theater," aus samtliche Werke, Band 5 (Mtunchen: Carl Hanser Verlag, 4. Auflage 1967), S. 816.

29 Bertolt Brecht, Schriften zum Theater 3 , s. 194. 30 Ebenda, S. 201.

${ }^{31}$ Bertolt Brecht, Schriften zum Theater 5, s. 36 .

32 Bertolt Brecht, Schriften zum Theater 3 , s. 282.

33 Bertolt Brecht, Schriften zur Literatur und Kunst 2. S. 202 .

\section{${ }^{34}$ Ebenda}

${ }^{35}$ Marianne Kesting, Bertolt Brecht in Selbstzeugnissen und Bilddokumenten (Hamburg: Rowohlt Verlag, 1973, 17. Auflage), S. $126 \mathrm{f}$.

\section{Kapitel X}

${ }^{1}$ Bertolt Brecht, "Der gute Mensch von Sezuan," Heft 12 der Versuche (Berlin: Suhrkamp Verlag, 1958), S. 60 .

2 Bertolt Brecht, "Die Dreigroschenoper," aus sttlcke fur das Theater am Schiffbauerdamm, Erster Band (Beriin: Suhrkamp Verlag, 1958), S. 60 .

3 Bertolt Brecht, "Me-ti, Buch der Wendungen," Prosa V (Frankfurt: Suhrkamp Verlag, 1965), S. $70 f$.

${ }^{4}$ Bertolt Brecht, "Funf Schwierigkeiten beim Schreiben der Wahrheit," Politische Schriften, S. 70.

${ }^{5}$ Peter Horst Neumann, Der Weise und der Elefant: Zwei Brecht-Studien (Munchen: Wilhelm Fink Verlag, 1970), S. $22 f$.

${ }^{6}$ Kohlhase, Dichtung und politische Moral, s. 36.

7 Neumann, Der Weise und der Elefant, s. 12.

8 Bertolt Brecht, Schriften zum Theater 2, s. 50 .

9 Bertolt Brecht, "Me-ti, Buch der Wendungen," s. 71. 10 Ebenda, s. 71 .

$11_{\text {Ebenda }}$ 
12 Bertolt Brecht, Schriften zum Theater 5, S. $48 f$.

13 Bertolt Brecht, Schriften zur Literatur und Kunst 3 . S. 104 .

14 Bertolt Brecht, "Me-ti, Buch der Wendungen," s. 42.

15 Ebenda, S. $120 f$.

${ }^{16}$ Bertolt Brecht, Schriften zum Theater 5, s. 38 .

${ }^{17}$ Bertolt Brecht, Schriften zur Literatur und Kunst 2. S. $57 f f$.

${ }^{18}$ Bertolt Brecht, "Me-ti, Buch der Wendungen," s. 177.

19 Ebenda

${ }^{20}$ Giese, Das "Gesellschaftlich-Komische," s. 87.

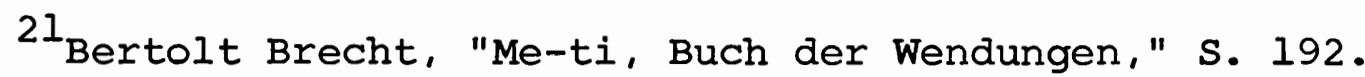

22 Dorothee solk, "Dialektik und Didaktik in Brechts Keunergeschichten," aus Brecht heute, Brecht Today, Jahrbuch der internationalen Brecht-Geselischaft, Jahrgang 2, 1972, Reinhold Grimm et al. Hsgb. (Frankfurt: Athenaum Verlag, $1972)$, S. 126.

23 Bertolt Brecht, Politische Schriften, s. $63 f$.

24 Bertolt Brecht, Uber Klassiker, s. 51 .

25 Bertolt Brecht, "Me-ti, Buch der Wendungen," s. 187.

${ }^{26}$ Ebenda, S. 166.

27 Bertolt Brecht, Schriften zum Theater 2, S. 28.

${ }^{28}$ Bertolt Brecht, "Me-ti, Buch der Wendungen," s. 61.

29 Ebenda, S. 63.

${ }^{30}$ Solle, "Dialektik und Didaktik," aus Brecht heute, S. 123 .

31 Bertolt Brecht, Gedichte 4. (1934-41) (Frankfurt: Suhrkamp Verlag, 1964), S. 143f.

32 Neumann, Der Weise und der Elefant, s. $10 f$.

${ }^{33}$ Bertolt Brecht, Gedichte 4. s. 51 . 
34 Bertolt Brecht, "Geschichten von Herrn Keuner," aus Geschichten (Frankfurt: Suhrkamp Verlag, 1962), S. 165.

${ }^{35}$ Bertolt Brecht, "Die Massnahme," aus stticke fthr das Theater am Schiffbauerdamm, 1927-1933 (Berlin: Suhrkamp Verlag, 1955), S. 304 .

${ }^{36}$ Bertolt Brecht, "Die Tage der Kommune," aus Stucke aus dem Exil, Band 5 (Berlin: Suhrkamp Verlag, 1957), S. 408 .

37 Bertolt Brecht, "Die Massnahme," aus stucke fur das Theater am Schiffbauerdamm, S. 290.

38 Bertolt Brecht, Politische Schriften, s. $20 f$.

${ }^{39}$ Neumann, Der Weise und der Elefant, s. 24.

40 Bertolt Brecht, Gedichte 4 , s. $143 f$.

${ }^{41}$ Bertolt Brecht, "Kleines Organon," aus Heft 12 der Versuche, s. 118 .

42 Ebenda, S. 131 .

43 Hans Magnus Enzensberger, "Weiterung," aus Blindenschrift (Frankfurt: Suhrkamp, 1965), S. 50.

${ }^{44}$ Hans Mayer, Das Geschehen und das Schweigen (Frankfurt: Suhrkamp Verlag, 1969), S. 30.

${ }^{45}$ Kohlhase, Dichtung und politische Moral, s. 80 .

${ }^{46}$ Jost Hermand, "Utopisches bei Brecht," aus BrechtJahrbuch 1974, John Fuegi et al., Hsgb. (Frankfurt: Suhrkamp Verlag, 1975), s. 32 .

47 Ebenda, S. 30 . 


\section{LITERATURVERZEICHNIS}

Angermayer, Hans Christoph. Zuschauer im Drama: BrechtDthrenmatt-Handke. Frankfurt: Athendum Verlag, 1971.

Arnold, Wilhelm u. a. Hsgb. Lexikon der Psychologie. Freiburg im Breisgau: Verlag Herder K. G., 1971.

Bahr, Gisela u. a. Hsgb. Brecht heute, Brecht Today: Jahrbuch der internationalen Brechtgesellschaft, Jahrgang 2, 1972. Frankfurt: Athenăum Verlag, 1972.

Bahr, Gisela. "Brecht in den siebziger Jahren - Themen und Thesen," in Brecht heute, Brecht Today: Jahrbuch der internationalen Brechtgesellschaft, Jahrgang 2, 1972. Gisela Bahr u. a. Hsgb. Frankfurt: Athenäum Verlag, 1972, 11-26.

Benjamin, walter. Versuche thber Brecht. Frankfurt: Suhrkamp Verlag, 1966.

Bräutigam, Kurt. Bertolt Brecht: Der qute Mensch von Sezuan. Mthchen: R. Oldenbourg Verlag, 4. Auflage, 1972.

Brecht, Bertolt. Arbeitsjournal. 2 Bd. Frankfurt: Suhrkamp Verlag, 1973.

- Erste Sttheke. Berlin: Suhrkamp Verlag, 1953.

- Gedichte IV, 1934-1941. Frankfurt: Suhrkamp Verlag, 1961 .

- Gedichte V, 1934-1941. Frankfurt: Suhrkamp Verlag, 1964.

"Gedichte aus dem Messingkauf" in Schriften zum Theater V. Frankfurt: Suhrkamp Verlag, 1963, $247-287$.

Auflage, 1963.

"Geschichten vom Herrn Keuner" in Heft 1-3 der Versuche. Frankfurt: Suhrkamp Verlag, 1959.

"Kleines Organon fur das Theater," in Heft 12 der Versuche. Berlin: Suhrkamp Verlag, 1958, 105-140. 
"Der Messingkauf," in Schriften zum Theater

V. Frankfurt: Suhrkamp Verlag, 1963, 5-181.

"Me-ti, Buch der Wendungen," in Prosa Band $\underline{\mathrm{V}}$. Frankfurt: Suhrkamp Verlag, 1965.

- Der Ozeanflug. Geschichten vom Herrn Keuner. Berlin: Suhrkamp Verlag, 1959.

- Politische Schriften. Ausgewählt von Werner Hecht. Frankfurt: Suhrkamp Verlag, 2. Auflage, 1972. 1965. Prosa, Band 3, 5. Frankfurt: Suhrkamp Verlag, Schriften zum Theater, Bd. I-V. Frankfurt: Suhrkamp Verlag, 1963-1964.

- Schriften zum Theater: Uber eine nicht-aristotelische Dramaturgie. Zusammengestellt von Siegfried Unseld. Berlin: Suhrkamp Verlag, 1957.

- Schriften zur Literatur und Kunst, Bd. 1-3. Frankfurt: Suhrkamp verlag, 1967.

1957. Stthcke aus dem Exil. Berlin: Suhrkamp Verlag,

- Stticke flir das Theater am Schiffbauerdamm.

Berlin: Suhrkamp verlag, 2. Auflage, 1957.

Uber Klassiker. Ausgewählt von Siegfried Unseld. Frankfurt: Insel Verlag, 1965.

Brockhaus Enzyklopädie. Dritter Band. Wiesbaden: F. A. Brockhaus, 1967.

Bunge, Hans. Fragen Sie mehr ther Brecht. Mthchen: Rogner und Bernhard, 1970 .

Enzensberger, Hans Magnus. Blindenschrift. Frankfurt: Suhrkamp Verlag, 1965.

Esslin, Martin. Bertolt Brecht. New York und London: Columbia University Press, 1969.

Brecht: Das Paradox des politischen Dichters. Frankfurt: Athendum Verlag, 1962 .

- Brecht: A Choice of Evils. A Critical Study of the Man, His Work and His Opinions. London: Eyre \& Spottiswoode, 3rd reprint, 1971. 
Ewen, Frederic. Bertolt Brecht: Sein Leben, sein Werk, seine Zeit. Ubersetzt von Klaus Dietrich Peterson und Hans Braun. Frankfurt: Suhrkamp Verlag, 1973.

Fodor, Nandor Hsgb. Freud: Dictionary of Psychoanalysis. Westport, Conn.: Greenwood Press Publishers, 1975.

Frisch, Max. Erinnerungen an Brecht. Berlin: Friedenauer Presse, Verlag der Wolff's Bthcherei, 1968.

Fuegi, John u. a. Hsgb. Brecht-Jahrbuch 1974. Frankfurt: Suhrkamp Verlag, 1975.

u. a. Hsgb. Brecht-Jahrbuch 1975. Frankfurt: Suhrkamp Verlag, 1975.

- The Essential Brecht. Los Angeles: Hennessey and Ingalls, Inc., 1972 .

Geissler, Rolf. "Bertolt Brecht," in Zur Interpretation des modernen Dramas, Rolf Geissler, Hsgb. , unter Mitarbeit von Therese Power und Wilhelm Ziskoven. Frankfurt: Verlag Moritz Diesterweg, 1960.

Giese, Peter Christian. Das "Gesellschaftlich-Komische." Zu Komik und Kombdie am Beispiel der stücke und Bearbeitungen Brechts. Stuttgart: J. B. Metzlersche Verlagsbuchhandlung, 1974.

Grimm, Jakob und Wilhelm. Deutsches worterbuch. Leipzig: S. Hirzel Verlag, 1860 .

Grimm, Reinhold. Bertolt Brecht: Die struktur seines Werkes. Nurnberg: Verlag Hans Carl, 1960 .

u. a., Hsgb. Brecht heute, Brecht Today. Jahrbuch der internationalen Brecht-Gesellschaft, Jahrgang 1, 1971. Frankfurt: Athenaum Verlag, 1971.

, Hsgb. Episches Theater. Koln-Berlin: Kiepenheuer \& Witsch, 1966.

"Notizen zu Brecht, Freud und Nietzsche," Brecht-Jahrbuch 1974, John Fuegi u. a., Hsgb. Frankfurt: suhrkamp verlag, 1975.

Das grosse Duden Lexikon. 2. Band. Mannheim: Lexikon Verlag, 1965 .

Grossvogel, David I. Four Playwrights and a Postscript: Brecht, Ionescu, Beckett, Genet. Ithaca, N.Y.: Cornell University Press, 1962. 
Haas, Willy. Bert Brecht. Berlin: Colloquium Verlag, 1958 .

Harvey, W. J. Character and the Novel. Ithaca, N.Y.: Cornell University Press, 1965.

Hecht, Werner Hsgb. Materialien zu Brechts "Leben des Galilei." Frankfurt: Suhrkamp Verlag, 1963.

Hehlmann, Wilhelm Hsgb. Worterbuch der Psychologie. Stuttgart: Alfred korner Verlag, 1974.

Hermand, Jost. "Herr Puntila und sein Knecht Matti," Brecht heute. Brecht Today. Jahrbuch der internationalen Brecht-Geselischaft, Jahrgang 1. Frankfurt: Athendum Verlag, 1971.

"Utopisches bei Brecht," in Brecht heute. Brecht Today. Jahrbuch der internationalen Brecht-Gesellschaft, Jahrgang 2, 1972. Frankfurt: Athendum Verlag, 1972 .

Hinck, Walter. "Die Dramaturgie des spatten Brecht," in Episches Theater. Hsgb. Reinhold Grimm. Koln-Berlin: Kiepenheuer \& Witsche, 1966.

Holthusen, Hans Egon. Kritisches Verstehen: Neue Aufsatze zur Literatur. Mtinchen: Piper \& Co. Verlag, 1961.

Jakobs, Jtirgen. "Wie die Wirklichkeit selber," in BrechtJahrbuch 1974, John Fuegi u. a. Hsgb. Frankfurt: Suhrkamp Verlag, 1975.

Jendreiek, Helmut. Bertolt Brecht: Drama der Verdnderung. Dússeldorf: August Bagel Verlag, 1969.

Kesting, Marianne. Bertolt Brecht in Selbstzeugnissen und Bilddokumenten. Hamburg: Rowohlt Verlag, 17. Auflage, 1959. Verlag, 1969 .

Kimble, Gregory A. and Norman Garmezy. Principles of General Psychology. New York: The Ronald Press Co.., 1963.

Klotz, Volker. Bertolt Brecht: Versuch tuber das Werk. Bad Homburg v. D. H., Berlin, Zurich: Verlag Gehlen, 1967.

Knopf, Jan. Bertolt Brecht: Ein kritischer Forschungsbericht. Frankfurt: Athenăum Verlag, 1974. 
Kohlhase, Norbert. Dichtung und politische Moral: Eine Gegentuberstellung von Brecht und Camus. Munchen: Nymphenburger Verlagshandlung, 1965.

Lindsey, Gardner und Calvin S. Hall. Psychology. New York: Worth Publishers Inc., $197 \overline{5}$

Mayer, Hans. Bertolt Brecht und die Tradition. Pfullingen: Verlag Güther Neske, 1961.

- "Brecht und die Humanitat," in Anmerkungen zu Brecht. Frankfurt: Suhrkamp Verlag, 1967.

"Brecht und Durrenmatt oder die Zurticknahme," in Durrenmatt und Frisch. Pfullingen: Verlag Gunther Neske, 2. Auflage, 1965.

- Deutsche Literatur seit Thomas Mann. Reinbek bei Hamburg: Rowohlt Verlag, 1967.

- Das Geschehen und das Schweigen. Frankfurt: Suhrkamp Verlag, 1969 .

Zur deutschen Literatur der Zeit. Reinbek bei Hamburg: Rowohlt Verlag, 1967.

Mews, Siegfried. "Brechts 'dialektisches Verhaltnis zur Tradition'. Die Bearbeitung des Michael Kohlhaas," in Brecht-Jahrbuch 1975, John Fuegi Hsgb. Frankfurt: Suhrkamp Verlag, 1975.

und Herbert Knust, Hsgb. Essays on Brecht:

Theater and Politics. Chapel Hill: The University of North Carolina Press, 1974.

Mtller, Klaus Detlef. Die Funktion der Geschichte im Werk Bertolt Brechts. Studien zum Verhyltnis von Marxismus und Asthetik. Tubingen: Max Niemeyer Verlag, 1967.

Mussen, Paul und Mark R. Rosenzweig. Psychology. An Introduction. Lexington, Mass. and Toronto: D. C. Heath and Co., 1974.

Neumann, Peter Horst. Der Weise und der Elefant: Zwei Brecht-studien. Mthnchen: Wilhelm Fink verlag, 1970.

Raddatz, Fritz J. "Entweiblichte Eschatologie," in Bertolt Brecht II, Sonderband aus der Reihe Text und Kritik, Hsgb. Ludwig Arnold. Munchen: Richard Boorberg Verlag, 1973, 152-159. 
Reich, Wilhelm. Character-Analysis. New York: The Noonday Press, a subsidiary of Farrar, Strauss and Cudahay, 1949.

Rosenbauer, Hansjthrgen. Brecht und der Behaviorismus. Bad Homburg V.D.H., Berlin, Zturich: Verlag Gehlen, 1970 .

Roth, Wolfgang. "Working with Bertolt Brecht," in Brecht heute. Brecht Today. Jahrbuch der internationalen Brecht-Gesellschaft, Jahrgang 2. Frankfurt: Athenaum Verlag, 1972, 131-135.

Rthlicke, Kathe. "Bemerkungen zur Schlusszene," in Materialien zu Brechts Leben des Galilei, Werner Hecht, Hsgb. Frankfurt: suhrkamp Verlag, 1963, 93-153.

Rtlicke-Weiler, Kathe. Die Dramaturgie Brechts: Theater als Mittel der Veränderung. Berlin: Henschel Verlag, 2. Auflage, 1968 .

Schiller, Friedrich. Die Ruuber. Munchen: Deutscher Taschenbuch Verlag, 1965.

"Die Schaubthne als eine moralische Anstalt betrachtet," in Schillers sumtliche Werke in zwblf Bänden, zehnter Band. Stuttgart und Tubingen: I. G. Cotta'scher Verlag, 1957.

"Uber das gegenwurtige teutsche Theater," Sumtliche Werke. Funfter Band. Mthchen: Carl Hanser Verlag, 4. Auflage, 1967.

- Uber naive und sentimentalische Dichtung. Stuttgart: Reclam Verlag, 1957.

"Was kann eine Schaubthne wirken?" in Schillers Werke, Nationalausgabe, 20. Band. Weimar: Hermann Buhlau Nachfolger, 1962.

Schumacher, Ernst. Drama und Geschichte: Bertolt Brechts "Leben des Galilei" und andere Stucke. Berlin: Henschel Verlag, 1965.

Die dramatischen Versuche Bertolt Brechts 1918-1930. Berlin: Rttten \& Loening, 1955 .

Solle, Dorothee. "Dialektik und Didaktik in Brechts Keunergeschichten," in Brecht heute. Brecht Today. Jahrbuch der internationalen Brecht-Gesellschaft. Jahrgang 2, 1972. Frankfurt: Athenaum Verlag, 1972, $121-130$. 
Sokel, Walter H. "Brecht's Concept of Character," Comparative Drama 5, No. 3, Fall 1971, 177-192.

Sternberg, Fritz. Der Dichter und die Ratio: Erinnerungen an Bertolt Brecht. Gottingen: Sachse und Pohl VerIag, 1963.

Szczesny, Gerhard. Das Leben des Galilei und der Fall Bertolt Brecht. Berlin: Verlag Ullstein, 1966.

Taeni, Rainer. Drama nach Brecht. Basel: Basilius Presse, Basler Druck und Verlagsanstalt. 1968.

Walcutt, Charles Child. "What is Character?" in Man's Changing Mask: Modes and Methods of Characterization in Fiction. Minneapolis: University of Minnesota Press, 1966, 5-19.

Wekwerth, Manfred. Schriften: Arbeit mit Brecht. Berlin: Henschel Verlag Kunst und Gesellschaft, 1973. 